\title{
Spatial and Temporal Characterization of Sea Surface Temperature Response to Tropical Cyclones*
}

\author{
WEI MEI \\ Department of Earth System Science, University of California, Irvine, Irvine, California \\ Claudia Pasquero \\ Dipartimento di Scienze Geologiche e Geotecnologie, Università di Milano-Bicocca, Milan, Italy
}

(Manuscript received 27 February 2012, in final form 15 November 2012)

\begin{abstract}
The spatial structure and temporal evolution of the sea surface temperature (SST) anomaly (SSTA) associated with the passage of tropical cyclones (TCs), as well as their sensitivity to TC characteristics (including TC intensity and translation speed) and oceanic climatological conditions (represented here by latitude), are thoroughly examined by means of composite analysis using satellite-derived SST data. The magnitude of the TC-generated SSTA is larger for more intense, slower-moving, and higher-latitude TCs, and it occurs earlier in time for faster-moving and higher-latitude storms. The location of maximum SSTA is farther off the TC track for faster-moving storms, and it moves toward the track with time after the TC passage. The spatial extension of the cold wake is greater for more intense and for slower-moving storms, but its shape is quite independent of TC characteristics. Consistent with previous studies, the calculations show that the mean SSTA over a TC-centered box nearly linearly correlates with the wind speed for TCs below category 3 intensity while for stronger TCs the SSTA levels off, both for tropical and subtropical regions. While the linear behavior is expected on the basis of the more vigorous mixing induced by stronger winds and is derived from a simple mixed-layer model, the level-off for intense TCs is discussed in terms of the dependence of the maximum amplitude of the area-mean SSTA on TC translation speed and depth of the prestorm mixed layer. Finally, the decay time scale of the TC-induced SSTA is shown to be dominated by environmental conditions and has no clear dependence on its initial magnitude and on TC characteristics.
\end{abstract}

\section{Introduction}

The strong winds associated with tropical cyclones (TCs) often generate a pronounced cooling at the sea surface during the TC passage, resulting in a cold wake left behind, as captured by both satellite and in situ measurements of sea surface temperature (SST) (Leipper 1967; Price 1981; Stramma et al. 1986; Shay et al. 1992; Nelson 1996; Jacob et al. 2000; Wentz et al. 2000; Zedler et al. 2002; D'Asaro 2003; D'Asaro et al. 2007; Sanford

\footnotetext{
* Supplemental information related to this paper is available at the Journals Online website: http://dx.doi.org/10.1175/JCLI-D-1200125.s1.

Corresponding author address: Wei Mei, Scripps Institution of Oceanography, University of California, San Diego, 9500 Gilman Drive \#0230, La Jolla, CA 92093-0230.

E-mail:wmei@ucsd.edu
}

et al. 2011). Research on the effects of TCs on the upper ocean, particularly on the SST, has a history of at least five decades, owing to its importance in both weather and climate context.

First, the TC-induced surface cold anomaly may significantly suppress the development of the TC itself through reduced energy supply, which is known as a negative feedback process (e.g., Bender et al. 1993; Schade and Emanuel 1999; Schade 2000; Cione and Uhlhorn 2003). The strength of this inhibiting effect on TC development depends on the magnitude of the cooling and the translation speed of the TC (Lin et al. 2009; Mei et al. 2012). This effect has been proven to be important for TC intensity prediction (e.g., Bender and Ginis 2000).

Second, the cold wake left behind a TC may affect the initiation and development of subsequent TCs, depending on its amplitude and persistence. A statistical study by Brand (1971) shows that the intensity of 
two-thirds (38 out of 57) of TCs under study was adversely influenced by the cold wake left behind former TCs. This adverse effect is demonstrated in a numerical study by Bender and Ginis (2000) of the intensity of Hurricane Fran (1996).

Third, the recovery of the cold anomaly has been proposed as a means of creating anomalous warming in the upper ocean. This is because the TC-induced surface cooling is mainly due to vertical mixing of the surface warm water and colder water underneath, producing a surface cold and a subsurface warm anomaly (e.g., Brooks 1983; Pudov 1993; Black et al. 2007; Sanford et al. 2007; Black and Dickey 2008). The surface cold anomaly decays much quicker than the subsurface warm anomaly after the TC passage (Nelson 1996; Hart et al. 2007; Price et al. 2008, hereafter P08; Pasquero and Emanuel 2008; Dare and McBride 2011, hereafter DM11), and at least part of the removal of the surface cooling is due to anomalous air-sea heat fluxes. Thus, the net effect of TCs is to pump heat into the ocean; the added heat then may be transported to other latitudes and released to the atmosphere, affecting the climate there (Emanuel 2001; Sriver and Huber 2007; Sriver et al. 2008; Pasquero and Emanuel 2008; Korty et al. 2008; Jansen and Ferrari 2009; Fedorov et al. 2010).

Moreover, the TC-induced surface temperature reduction may influence the overlying local atmospheric processes, such as deep convection, and cumulatively may affect the mean state of the Hadley circulation (e.g., Sriver and Huber 2010) owing to the considerably large area of the sea surface the TCs affect each year (Hart 2011). Changes in tropical atmospheric circulation may propagate into higher latitudes as large-scale Rossby waves (e.g., Lachlan-Cope and Connolley 2006), and thus, the TC-induced surface cooling may affect weather and climate remotely. Recently, it has also been recognized that the TC-induced sea surface cooling helps reduce the thermal stress on coral reefs, and correspondingly, it mitigates their bleaching (Manzello et al. 2007; Carrigan and Puotinen 2011). The above-listed reasons demonstrate the great importance of having a comprehensive description of the magnitude, the spatial extension, and the persistence of the surface cold anomaly generated by TCs.

Previous work on TC-induced SST anomaly (SSTA) mainly focused on its local maximum amplitude and spatial structure. The local maximum value of the cooling reported in different case studies varies significantly, from less than $1^{\circ} \mathrm{C}$ to greater than $10^{\circ} \mathrm{C}$ (e.g., Price 1981; Chiang et al. 2011). Processes responsible for the cooling [including vertical mixing, air-sea heat extraction, and advection (e.g., Huang et al. 2009)] and, thus, the amplitude of the cooling strongly depend on TC intensity, TC translation speed, and prestorm upper-ocean thermal structure (e.g., Price 1981; Shay et al. 2000; Mao et al. 2000; Morey et al. 2006). Exploration of the spatial structure of the SSTA has revealed that the largest cooling is often found off the TC track (e.g., Price 1981). The rightward shift in the Northern Hemisphere can be attributed to two factors. First is that on the right side of the track, the clockwise rotation of the wind stress with time at a fixed location tends to strengthen the windinduced inertial currents in the upper ocean that, in the Northern Hemisphere, also exhibit a clockwise rotation, leading to enhanced shear-induced vertical mixing and, hence, a stronger SSTA (e.g., Price et al. 1994). Second is that superimposition of the translation speed onto the TC wind speed results in stronger winds in terms of the absolute value on the right side of the track than those on the left (e.g., Hazelworth 1968). The extent of the shift depends on the translation speed of the TC (Price 1981; Zedler 2009; Mei et al. 2012).

Owing to the transient character of a TC, the cold SSTA reaches a peak and then it decays, as the perturbed upper ocean is in an unbalanced state. Persistence of the SSTA, or equivalently recovery of the SST, is another research area associated with the TC-induced SST cooling (Hazelworth 1968; Hart et al. 2007; P08). For example, using satellite and drifter data, P08 obtain for the SST recovery an $e$-folding time of 5-20 days.

The above-mentioned work mostly focuses on individual cases, and accordingly, the results reported vary considerably, as noted earlier. Recently, composite techniques have been used to acquire information on the average effect of TCs on the SST. The composite technique smoothes out the variability associated with mesoscale and submesoscale structures present in the ocean and leads to more meaningful conclusions by enhancing the signal-to-noise ratio. To our knowledge, Hart et al. (2007) are the first to use a composite procedure to study the mean SST response averaged over a TC-centered $5^{\circ} \times 5^{\circ}$ box to the TC passage and the subsequent SST recovery in the Northern Hemisphere. They find that the amplitude of the SST cooling depends on TC intensity, and that the cooling generally persists for a period of 35-40 days. These findings were later consolidated by Schenkel and Hart (2010, 2011). However, the SST data used, the Reynolds SSTs, may not be able to capture the signal during and right after the TC passage because of the masking effect on infrared measurements of cloud cover and heavy rains. More recently, Lloyd and Vecchi (2011) have used the SSTs from the Tropical Rain Measuring Mission (TRMM) Microwave Imager (TMI) and repeated the calculation. Because of both higher accuracy of TMI SST data and a smaller box $\left(1^{\circ} \times 1^{\circ}\right)$ in use, they find a greater SSTA 
for TCs of same intensity compared to Hart et al. (2007). In addition, they note a shorter period of SST recovery.

Until now, the most thorough investigation of the amplitude of the TC-induced SSTA, the recovery of the SST after the TC passage, and their respective dependence on TC intensity and translation speed is conducted by DM11. DM11 show many interesting features, including the distribution of the time of maximum cooling relative to the $\mathrm{TC}$ passage and of the recovery time of the SST after the TC passage. However, as noted in Hart et al. (2007), the Reynolds SSTs may not be reliable in studying the SST response during the TC passage. Moreover, because their primary interest is in the cooling of SST right below the TC eye, where changes in heat fluxes may have the most significant impact on the TC development, only the evolution of the SST at the point right at the TC center was examined. As discussed in their conclusion section, this may underestimate the impact of TCs on the SST. Also, caution needs to be taken when studying the SST recovery based on a limited areal extension, as many processes, including eddy displacement and propagation of the cold anomaly (e.g., Jansen et al. 2010), can significantly distort the results.

The purpose of this study is to characterize the SST response to the TCs in a more comprehensive and systematic way based on composite analysis of more reliable SST data. After presenting the data and methods in use (section 2), we describe the spatial structure of the TC-induced SST cooling, including the local maximum amplitude, its location relative to the track, and the width of the anomaly, and then we study their respective dependence on TC intensity, TC translation speed, and latitude (section 3). This, to our knowledge, has never been addressed before. We then explore the dependencies of the magnitude of the areal mean SST cooling (section 4). Finally, we explore the temporal evolution of the SSTA, including the timing of the maximum amplitude of the cooling, the recovery time scale of the SST, and the evolution of the structure of the cold wake (section 5).

\section{Data and method}

\section{a. Sea surface temperature data and tropical cyclone track data}

SSTs are from TMI (Wentz et al. 2000). This product covers the region between $40^{\circ} \mathrm{S}$ and $40^{\circ} \mathrm{N}$ with a spatial resolution of $0.25^{\circ} \times 0.25^{\circ}$, and, relying on microwave measurements, is not limited to cloud-free regions. It has been available since December 1997 and has a daily temporal resolution including ascending and descending orbit segments. The daily average value is obtained by averaging the ascending and descending passes or assigning the available one if only one pass is available. Missing values are left unfilled. Residual SST values, used for the rest of the paper, are computed at each location after the removal of the seasonal cycle and the long-term linear trend.

TC track data are from the National Hurricane Center best track dataset (McAdie et al. 2009) and the Joint Typhoon Warning Center best track dataset (Chu et al. 2002), which provide the location and intensity of global TCs at 6-h intervals. To be consistent with the availability of the TMI SST data, only the track data from December 1997 until 2009 are used. The translation speed is computed by dividing the sum of the respective distance the TC moves 6 - $\mathrm{h}$ prior to and 6-h after reaching the current position by the total time interval (12 h); for the starting and ending positions of the life time of a TC, it is determined by forward and backward differencing the positions at 6-h intervals, respectively. All stages of the TC life cycle (i.e., from tropical depression through category 5 hurricane) are considered in our analysis. Note that throughout the paper we use the term hurricane to indicate a TC that has maximum 1-min sustained surface wind speed above $33 \mathrm{~m} \mathrm{~s}^{-1}$, regardless of its origin area. Only TCs located equatorward of $35^{\circ}$ are considered to minimize the influence of strong currents (e.g., the Gulf Stream), with their associated strong lateral temperature gradients, on our estimate of the decay time scale of the TC-induced SSTA.

\section{b. Methods}

Composite analysis is used to obtain the mean features of the SST response. Two composite procedures are used. For the first one, for each 6-h TC location we define a domain centered on the TC center and with size $2500 \mathrm{~km}$ along the direction perpendicular to the TC track and around $200 \mathrm{~km}$ along the direction parallel to the track (see the gray area in Fig. 1 for an example). We then construct a grid within the domain with spatial resolution of around $10 \mathrm{~km} \times 10 \mathrm{~km}$. After removing those extending over land, there are nearly 28000 domains in total for the study period (Table 2). Then the residual daily TMI SST data are linearly interpolated onto those grids, producing a spatial map of SST for each TC location and each analyzed day. Those maps are composited based on the date with respect to the time of the TC passage. The composite is performed from 2 months before the TC passage and until 4 months after. The SSTA is calculated with respect to the mean residual SST value obtained by averaging over the month before the TC passage. Hereafter, we will refer to the products of this procedure as the composite maps of SSTA. Their purpose is to fully characterize the spatial 


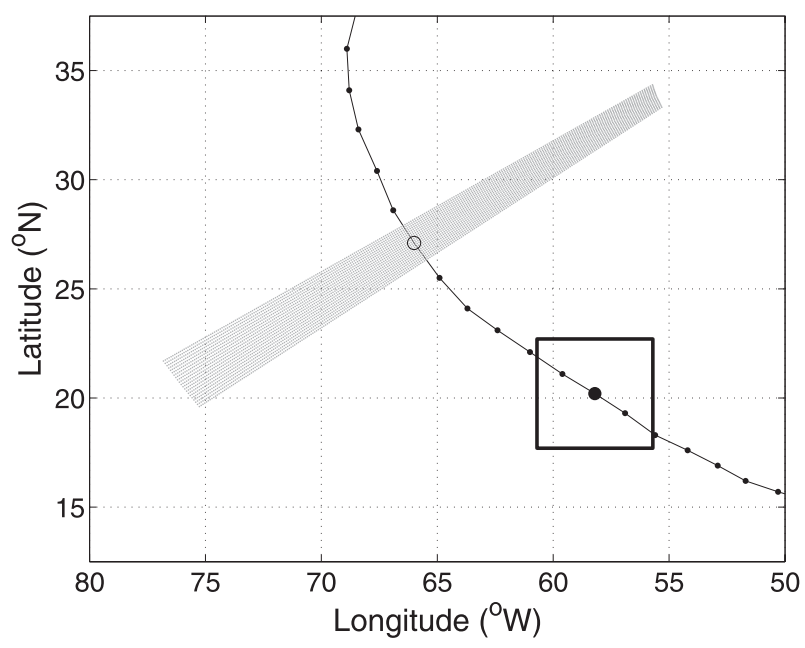

FIG. 1. Illustration of the two domain types used for the composite analysis, shown on the track of Hurricane Bill (2009). The gray area indicates the domain used for the spatial composite and centered on the storm location denoted by an open circle. Within this domain, grid points with a resolution of approximately $10 \mathrm{~km} \times 10 \mathrm{~km}$ are constructed with the two coordinates, respectively, parallel and perpendicular to the storm track (the tiny grid points can be more clearly seen when the figure is zoomed in). Thick black lines indicate the box used for the area-mean composite analysis, and the box is centered on the storm location denoted by a big black dot. The box has a size of $5^{\circ}$ in latitude and $5^{\circ}$ in longitude.

structure of the typical SST cooling and of its temporal evolution.

To better characterize the amplitude of the SSTA and to directly compare with previous studies, we also perform an area-mean composite following the procedure used by Hart et al. (2007). First, for each TC location, a $5^{\circ} \times 5^{\circ}$ box is defined around the TC center. Holding the location of the box fixed, the mean SST $\left\langle T^{\prime}\right\rangle$ is calculated from the $\sim 400$ SST grid points in the box (here, an angular bracket indicates a spatial average over the box, and a prime refers to the temporal anomaly with respect to the sum of the climatological seasonal cycle and the linear trend over the whole length of the time series). Then the evolution of these mean values is calculated starting from 2 months before the TC passage and until 4 months after, for a total of 181 daily SST data for each box. Then for each box the SSTA is calculated with respect to the mean SST value obtained by averaging over the month before the TC passage. Finally, the obtained evolutions of mean SSTA for each box are used to perform the composite analysis based on TC intensity and/or translation speed.

\section{Spatial structure of the SST response}

The spatial structure of the TC-induced SST response has been widely studied in literature via case studies (e.g.,
Price 1981). Probably the most well-known feature is the rightward-shifted cold wake in the Northern Hemisphere, as discussed before. Here we begin our analysis with examining whether this feature is present in the composite maps of SSTA. We show in Fig. 2 the spatial pattern of the composited SSTA generated by hurricanes on the day after the passage, when the anomaly peaks. The asymmetry of the SSTA is well reproduced, with rightward (leftward) shifts in the Northern (Southern) Hemisphere. The center of the SSTA is located about $50 \mathrm{~km}$ away from the TC track. Note that the SSTA is relatively uniform along the track in our maps, indicating that our spatial composite procedure works well. Next we examine in detail the local maximum amplitude of the SSTA, its location with respect to the track, the width of the anomaly, and their respective dependencies.

\section{a. Local maximum magnitude}

Figures $3 \mathrm{a}$ and $3 \mathrm{~b}$ show the cross-track profiles of the SSTA, centered at the storm position on the previous day, in response to TCs of different intensities. Generally, stronger TCs generate more intense sea surface cooling in both hemispheres. For example, in the Northern Hemisphere, the average local maximum cooling produced by a category $3-5$ hurricane is $2.6^{\circ} \mathrm{C}$, while the maximum in the SSTA left behind a tropical depression is less than $0.5^{\circ} \mathrm{C}$. This dependence also holds for the Southern Hemisphere.

The local maximum amplitude of the SSTA also strongly depends on the TC translation speed. Figure $4 \mathrm{a}$ shows the TC-induced SSTA as a function of cross-track distance and TC translation speed for hurricanes in the Northern Hemisphere. It shows that hurricanes moving at $1 \mathrm{~m} \mathrm{~s}^{-1}$ typically produce a local maximum cooling larger than $4^{\circ} \mathrm{C}$ in their wake, whereas hurricanes moving at $8 \mathrm{~m} \mathrm{~s}^{-1}$ on average generate a maximum cooling of $1.5^{\circ} \mathrm{C}^{1}$

We now examine the latitudinal dependence of the TC-generated sea surface cooling. The climatological (or prestorm) mixed-layer depth has strong latitudinal variations in areas where TCs are active (e.g., de Boyer Montégut et al. 2004), which is known to affect the magnitude of the TC-induced SSTA. Figure 5 shows the

\footnotetext{
${ }^{1}$ We recently showed that TC intensity on average correlates with its translation speed: faster-moving TCs typically become stronger (Mei et al. 2012). This indicates that when the TC intensity is fixed, the effect of translation speed on the magnitude of the SSTA may be even more significant than suggested by the values reported above: the slow-moving TCs, which generate a relatively large sea surface cooling, are typically weaker than the fast-moving TCs.
} 
(a) SSTA (NH)

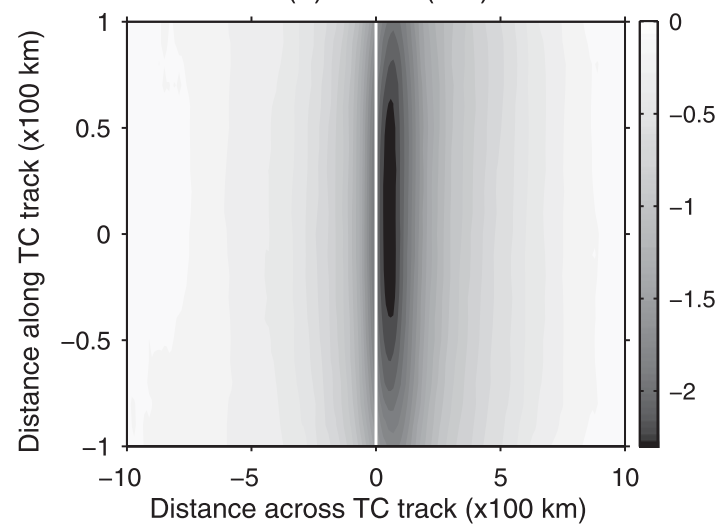

(b) SSTA (SH)

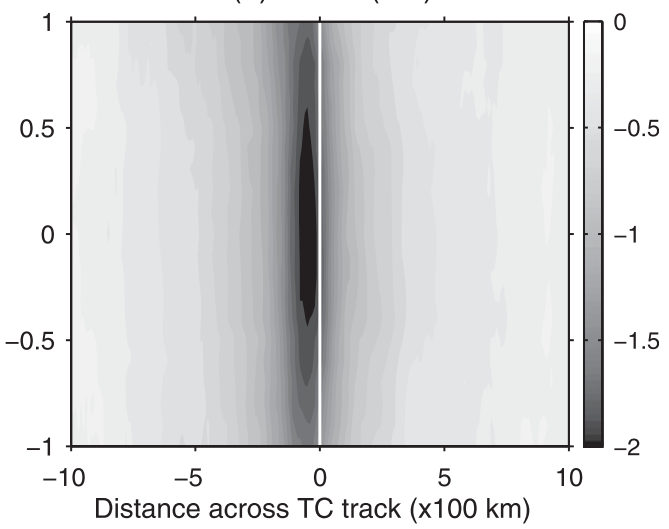

FIG. 2. Spatial pattern of the composite SSTA $\left({ }^{\circ} \mathrm{C}\right)$ associated with the passage of category $1-5$ hurricanes in the (a) Northern and (b) Southern Hemispheres on the day after the cyclone passage when the SSTA near the storm center peaks.

cross section of the zonal-averaged temperature over the TC active area in the western North Pacific. It shows that a deep warm pool exists in the tropics with a 50-mdeep mixed layer, while at higher latitudes, strong meridional temperature gradients and a much shallower mixed layer are present. The transition zone is centered around $20^{\circ} \mathrm{N}$. Thus, we simply take $20^{\circ}$ as a separation latitude $^{2}$ and examine the latitudinal dependence of the SST response to TCs. We will refer to the area equatorward of $20^{\circ}$ as the tropical ocean and the one poleward as the subtropical ocean.

Figure $4 \mathrm{~b}$ shows the SSTA as a function of both crosstrack distance and TC translation speed for hurricanes in the subtropics of the Northern Hemisphere. Generally, TCs of a given intensity and translation speed generate stronger SST cooling in subtropics, owing to the shallower prestorm mixed layer. For example, we can see, by comparing Figs. $4 \mathrm{a}$ and $4 \mathrm{~b}$, that a hurricane with translation speed of $1 \mathrm{~m} \mathrm{~s}^{-1}$ leads, on average, to a nearly $5^{\circ} \mathrm{C}$ local cooling in the subtropics, while the corresponding value for the tropics is less than $3.6^{\circ} \mathrm{C}$ (not shown).

\section{b. Location of maximum anomaly}

To better identify the location of the local maximum cooling, we show in Figs. 3c and 3d the cross-track profiles of the normalized SSTA for TCs of different intensity. Interestingly, in the Northern Hemisphere the maximum cooling is located $60 \mathrm{~km}$ to the right of the TC track, independent of the TC intensity. Note however

\footnotetext{
2 Actually, as will be shown in the next section, another reason for choosing $20^{\circ}$ is that the dependence of the SST response on TC translation speed is different for tropical depressions and tropical storms in regions equatorward and poleward of $20^{\circ}$. Moving the separation latitude equatorward or poleward by a couple of degrees does not significantly change the results.
}

that the spatial resolution of the SST data in use is $0.25^{\circ} \times 0.25^{\circ}$, and hence, small fluctuations in the location of maximum cooling, if present, cannot be observed. The independence of the extent of the off-track shift $(50 \mathrm{~km}$ to the left) on TC intensity holds true for the Southern Hemisphere, except for tropical depressions that lead to a more distant maximum cooling from the track. This exception is possibly because of the small signal-to-noise ratio of the SSTA induced by tropical depressions and/ or because of the fact that the radius of maximum winds for tropical depressions is larger than that for more intense TCs (see Fig. 15 in Kimball and Mulekar 2004).

By contrast, the extent of the off-track shift in SSTA strongly depends on the TC translation speed (Fig. 4). The faster the TC moves, the stronger the shift. For instance, the cold wake produced by a hurricane moving at $1 \mathrm{~m} \mathrm{~s}^{-1}$ is almost symmetric with respect to the TC track, while the center of the cold wake generated by a hurricane of the same intensity but with a translation speed of $8 \mathrm{~m} \mathrm{~s}^{-1}$ is shifted to the right of the track by $100 \mathrm{~km}$. This dependence holds true for TCs of other intensities and in the Southern Hemisphere (not shown). These results give observational support to the numerical study of Zedler (2009), who attributes the dependence of the extent of the asymmetry to the more symmetric kinetic energy input on the two sides of the TC track for slow-moving TCs.

The extent of the shift exhibits almost no dependence on latitude when the translation speed is fixed. This can be drawn from a comparison of Figs. $4 \mathrm{a}$ and $4 \mathrm{~b}$ and is confirmed by a comparison between the situation in the tropics (not shown) and that in the subtropics (Fig. 4b).

\section{c. Width of the cold anomaly}

Visual inspection of cold wakes in case studies suggests that the area impacted by TCs is larger for cases 
(a) SSTA (NH)

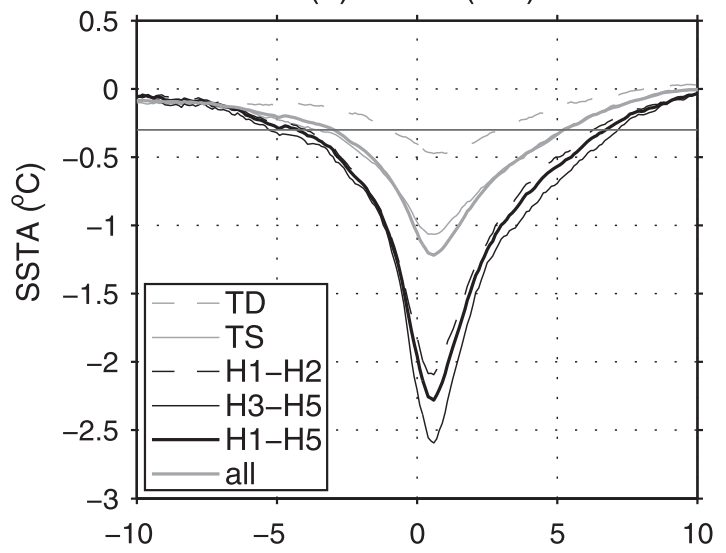

(c) Scaled SSTA (NH)

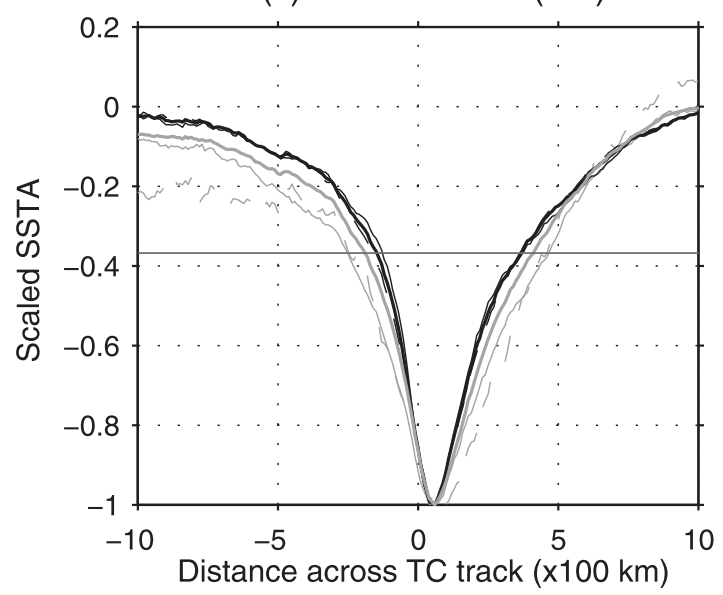

(b) SSTA (SH)

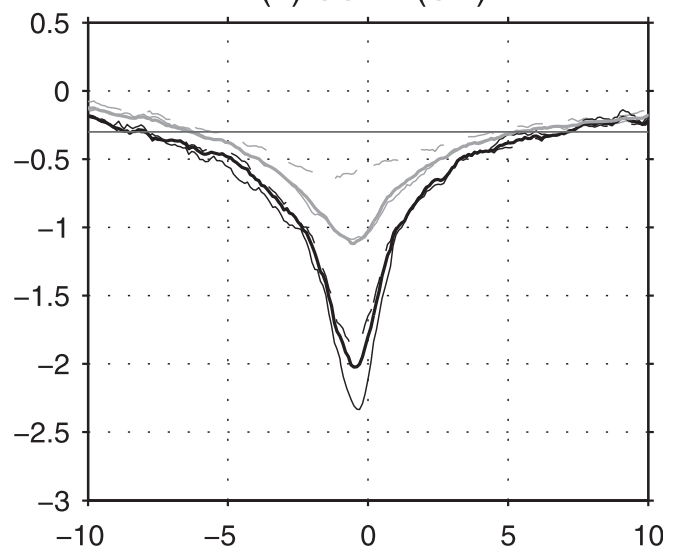

(d) Scaled SSTA (SH)

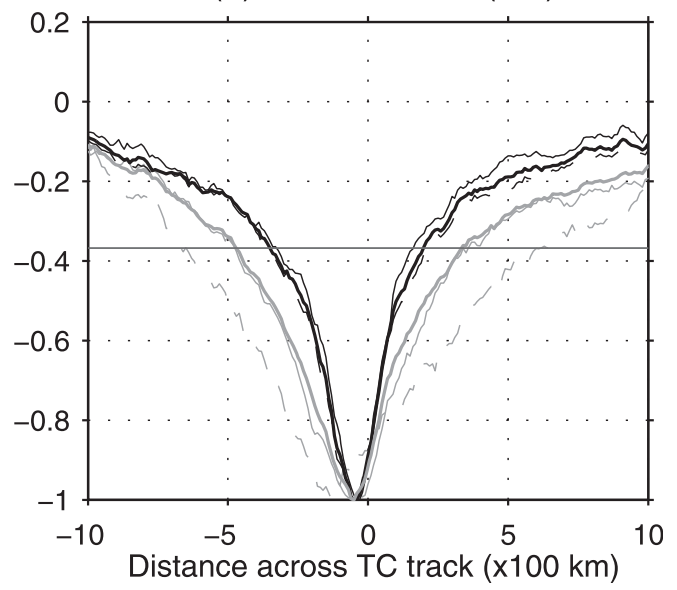

FIG. 3. (a),(b) TC-induced SSTA as a function of the distance across the TC track on the day after the cyclone passage when the SSTA near the storm center peaks. The horizontal solid lines indicate SSTA $=-0.3^{\circ} \mathrm{C}$. (c), (d) As in (a) and (b), but for the SSTA scaled by the maximum value across the track. The horizontal solid lines indicate the normalized SSTA $=-e^{-1}$. The left panels are for Northern Hemisphere, and the right panels are for Southern Hemisphere. Abbreviations: TD, tropical depression; TS, tropical storm; H1-H2, category 1-2 hurricane; H3-H5, category 3-5 hurricane; and $\mathrm{H} 1-\mathrm{H} 5$, category 1-5 hurricane.

with larger local maximum SSTA. This characterization is affected by the difficulty of defining the impacted area, given the large variability of SST present at any time in the ocean that masks the detection of weak-TC-induced wakes. The composite procedure, by averaging out most of the random noise, allows us to perform a more systematic study of the size and shape of the impacted area. As a measure of the size of the cold wake, we use the distance between two points located on each side of the TC track at which the SSTA is $-0.3^{\circ} \mathrm{C}^{3}$ Results for the composite maps conditioned to the TC intensity are

\footnotetext{
${ }^{3}$ Using a threshold of slightly different values (e.g., $-0.25^{\circ}$ or $-0.4^{\circ} \mathrm{C}$ ) does not change the general statement, though the detailed values of the width of the cold wake may vary.
}

reported in Table 1 (see also Figs. 3a,b). Clearly, the size of the wake increases with the TC intensity. This may be due to the fact that stronger TCs on average have a larger size (Kimball and Mulekar 2004) (see also Fig. 6 for the dependence of the averaged radius of outer closed isobar on TC intensity using the latest available data).

However, the shape of the cold wake is very similar in all cases. To study the shape of the cold wake, we use as metrics the distance between two points located on each side of the TC track at which the SSTA drops to $e^{-1}$ times the local maximum amplitude of the SSTA, and we refer to it as the width of the normalized wake. With the aid of horizontal solid lines in Figs. 3c and 3d, we can see that, generally, the normalized cold wake has a width of around $550 \mathrm{~km}$. Storms inducing smaller local maximum SSTA do not produce narrower normalized wakes; 
(a)

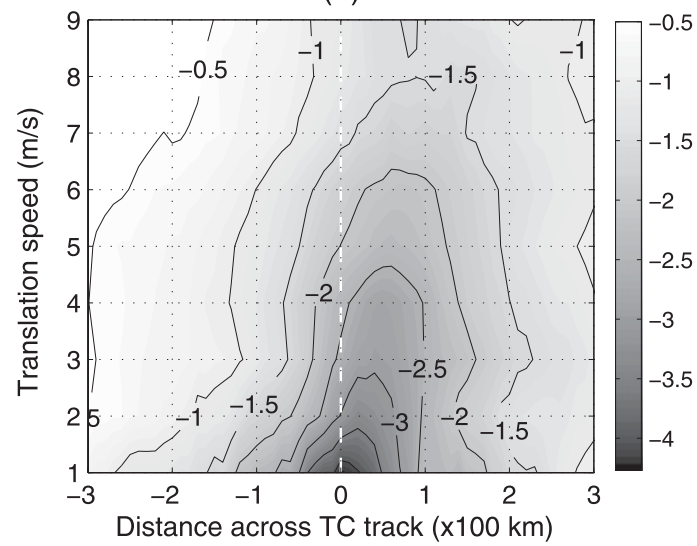

(b)

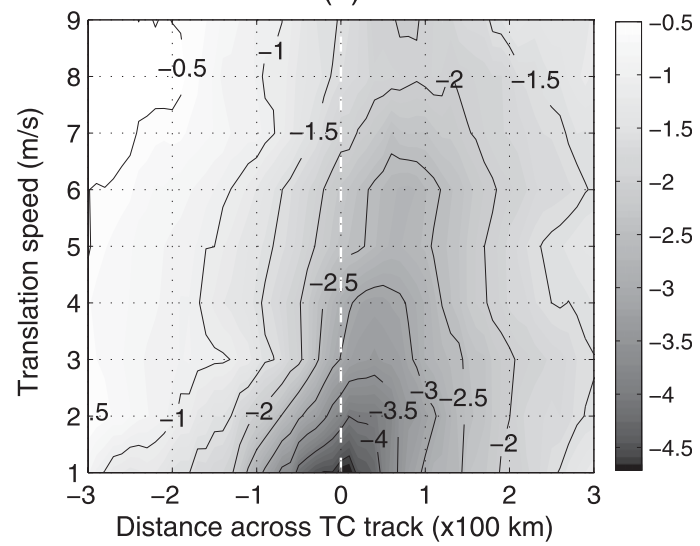

FIG. 4. Hurricane-induced SST response $\left({ }^{\circ} \mathrm{C}\right)$ in the Northern Hemisphere on the day following the storm passage as a function of the distance across the TC track and the translation speed of the TC: (a) total area and (b) subtropical region.

on the contrary, stronger TCs lead to cold wakes with narrower shape, while the cold wakes left behind weak TCs are more diffuse (see also Table 1). Equivalently, this means that the gradient in the normalized SSTA is greater in the cold wake of stronger TCs. Such a dependence on TC intensity appears to be much stronger for the Southern Hemisphere than for the Northern Hemisphere. For example, in the Southern Hemisphere the normalized cold wakes generated by tropical depressions and hurricanes have a width of 1290 and $550 \mathrm{~km}$, respectively, while in the Northern Hemisphere their respective width is 710 and $520 \mathrm{~km}$. However, we are not sure whether this difference reflects a fundamentally different mechanism operating in the two hemispheres or if it is merely an artifact associated with the relatively small number of TCs in the Southern Hemisphere, which leads to a smaller signal-to-noise ratio for the SSTA induced by weak storms in the Southern Hemisphere.

Analogously, the width of the normalized cold wake produced by a slow-moving storm is smaller than that produced by a fast-moving storm (not shown). This is because of the stronger local maximum cooling and, thus, the larger temperature gradient in the cross-track direction of the wake generated by slower-moving TCs.

Analysis of the cold wake separately for tropical and subtropical regions shows that the width of the cold wake has almost no dependence on latitude (not shown).

Overall, we can conclude that although TCs that induce more intense cooling generate a bigger size wake, the shape of the wake is quite similar for all the cases, and the wake is almost perfectly scaled by the maximum SSTA, with a small difference indicating that smaller amplitude wakes have a slightly broader shape.

\section{Maximum magnitude of the area-averaged SSTA}

Case studies reported in the literature typically present the local maximum SSTA observed after the TC passage as a measure of its impact. This figure is particularly indicative for intense storms, but it is also highly affected by the storm-independent SST variability present in the ocean. Thus, an integral measure of the SSTA over the whole impacted area is also a quantity of interest, as it reduces the noise level associated with mesoscale and submesoscale oceanic structures. In this section, we present the maximum magnitude of the area-mean SST

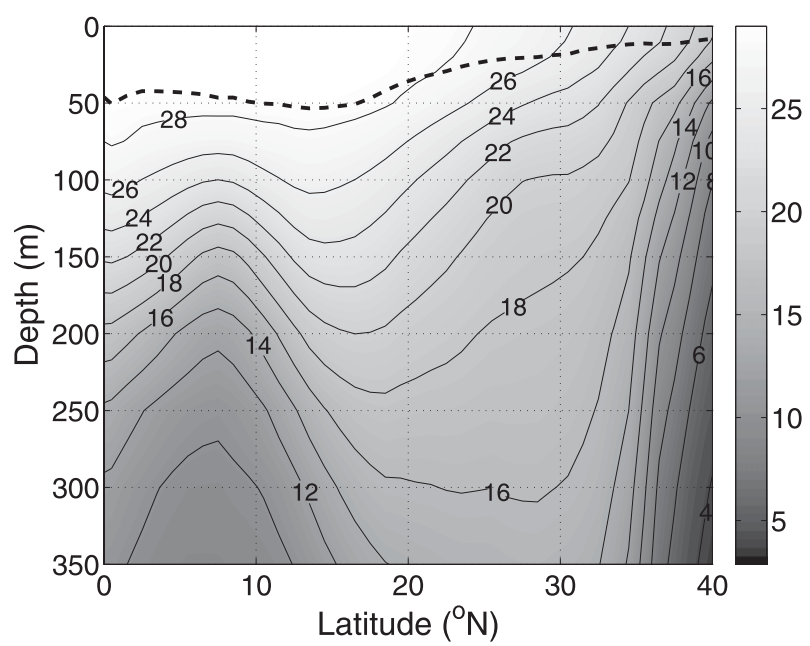

FIG. 5. The cross section of zonally averaged climatological temperature $\left({ }^{\circ} \mathrm{C}\right)$ in the TC active area in the western North Pacific calculated using data from World Ocean Atlas 2009. Dashed curve denotes the mixed-layer depth, which is defined as the depth at which the temperature is $0.5^{\circ} \mathrm{C}$ lower than surface temperature. 
TABLE 1. Mean width of the composite cold wake generated by tropical cyclones (units are $100 \mathrm{~km}$ ).

\begin{tabular}{lcccc}
\hline \hline & $\begin{array}{c}\text { Northern Hemisphere } \\
\left(-0.3^{\circ} \mathrm{C}\right)\end{array}$ & $\begin{array}{c}\text { Northern Hemisphere } \\
(\text { normalized })\end{array}$ & $\begin{array}{c}\text { Southern Hemisphere } \\
\left(-0.3^{\circ} \mathrm{C}\right)\end{array}$ & $\begin{array}{c}\text { Southern Hemisphere } \\
(\text { normalized })\end{array}$ \\
\hline Tropical depression & 4.1 & 7.1 & 10.3 & 11.7 \\
Tropical storm & 8.7 & 7.2 & 15.2 & 8.4 \\
Category 1-2 hurricane & 10.3 & 5.3 & 15.2 & 5.7 \\
Category 3-5 hurricane & 12.5 & 5.0 & 15.2 & 4.9 \\
Category 1-5 hurricane & 11.0 & 5.2 & 11.7 & 5.5 \\
All storms & 8.2 & 6.0 & 8.1 \\
\hline
\end{tabular}

cooling associated with the TC passage and discuss its dependence on TC intensity and translation speed and on latitude in more detail. As described in section $2 \mathrm{c}$ and unless stated otherwise, the area refers to a $5^{\circ} \times 5^{\circ}$ box centered at the TC center. The reason for a choice of $5^{\circ}$ is that generally the width of TC-induced cold wake has a width of comparable size (see section 3c). We do not compute the area-mean SSTA on the composite maps used for the previous section for two reasons: 1) the use of a latitude/longitude box is simpler and computationally more efficient, and 2) to study the temporal evolution of the area-mean SSTA, it is important to have a large-enough box so that the probability of having the cold anomaly advected out of the box is reduced. Jansen et al. (2010) note that those cold anomalies typically propagate westward at a speed of $0.1^{\circ} \mathrm{day}^{-1}$, so if we want to follow them for a couple of months, the box needs to be around $5^{\circ}$ in length. However, extending the domain used for the spatial composites in the along-track direction will introduce more errors and shows no improvement over the use of a latitude/longitude box. The maximum $5^{\circ} \times 5^{\circ}$ box area-mean cold anomaly is $0.72^{\circ} \mathrm{C}$ if averaged over all TCs (Table 2), but it has a strong dependence on TC characteristics, as we show next.

\section{a. Dependence on TC intensity}

\section{1) Observations}

Reflecting the results for the local maximum SSTA, the maximum value of the area-mean SSTA strongly depends on TC intensity (Table 2). For example, the mean change of SST within a $5^{\circ} \times 5^{\circ}$ area induced by category 3-5 hurricanes exceeds $1.4^{\circ} \mathrm{C}$, while the mean SST drop due to tropical storms is only $0.7^{\circ} \mathrm{C}$. [Corresponding figures reported in Schenkel and Hart (2010) are $0.56^{\circ}$ and $0.3^{\circ} \mathrm{C}$ based on the Reynolds SST data. The difference is probably because of the lack of data under cloudy conditions in the Reynolds data, resulting in an underestimate of the magnitude of the anomaly.] The magnitude is clearly smaller than the local maximum amplitude $\left(2.6^{\circ}\right.$ and $1.1^{\circ} \mathrm{C}$, respectively), as here we are averaging the anomaly over an area that covers small anomalies as well as the maximum local anomaly.
To better quantify the relation between the intensity of TCs and the maximum amplitude of the area-mean SSTAs they generate, we further divide TCs into bins of $5 \mathrm{~m} \mathrm{~s}^{-1}$ according to their maximum sustained surface winds and repeat the composites for each bin. Figure 7a displays the results. The positive relationship between TC intensity and their induced SSTA is more evident: in fact, the relationship is almost linear for TCs with maximum sustained wind weaker than $50 \mathrm{~m} \mathrm{~s}^{-1}$. Interestingly, the SSTA that left behind stronger TCs (i.e., category 3-5 hurricanes) levels off and exhibits no significant dependence on TC intensity.

To test whether these features are artificial owing to the specific box size in use, we repeat the composite using boxes of different sizes (from $1^{\circ} \times 1^{\circ}$ to $9^{\circ} \times 9^{\circ}$; Fig. 8a). Using smaller boxes results in a larger SSTA since the strongest SSTA is present around the TC track

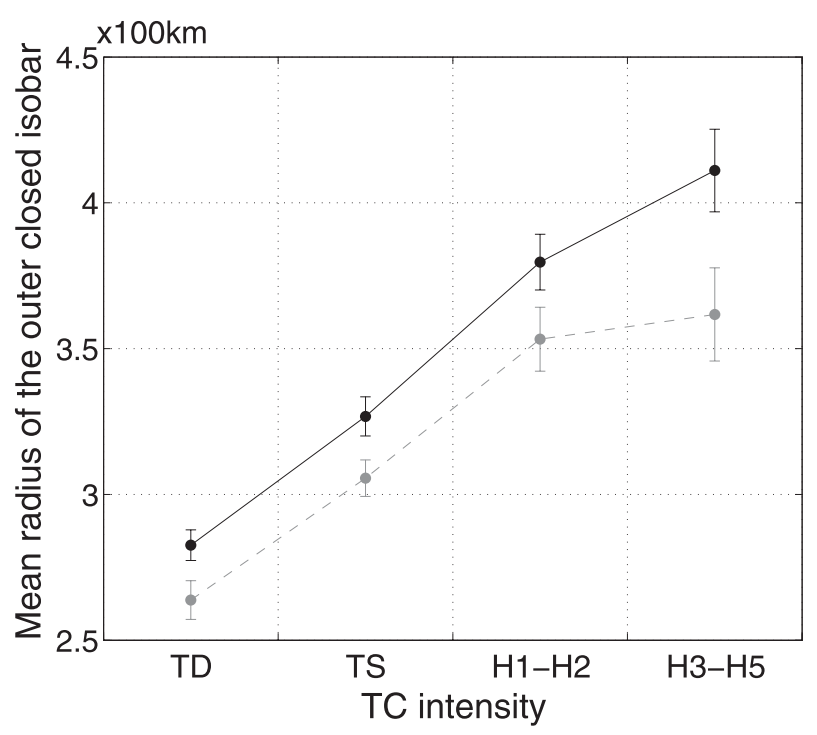

FIG. 6. The averaged radius of the outer closed isobar as a function of TC intensity for TCs in the North Atlantic (solid curve; 1988-2010) and in the eastern North Pacific (dashed curve; 200110). The error bars are calculated by dividing their standard deviation by the square root of the number of storms (a lower bound for the number of independent observations). The data are from the Tropical Cyclone Extended Best Track Dataset (Demuth et al. 2006). 
TABLE 2. Statistics of composite SSTA averaged within a $5^{\circ} \times 5^{\circ}$ box.

\begin{tabular}{|c|c|c|c|c|}
\hline Storm intensity & $\begin{array}{l}\text { Number of boxes } \\
\text { for composite }\end{array}$ & $\begin{array}{l}\text { Number of storms } \\
\text { for composite }\end{array}$ & Maximum cooling $\left({ }^{\circ} \mathrm{C}\right)^{*}$ & $\begin{array}{l}\text { Recovery } e \text {-folding } \\
\text { time (days)** }\end{array}$ \\
\hline Tropical depression & 10920 & 1078 & $0.376 \pm 0.023$ & $9.9 \pm 0.7(9.0 \pm 0.6)$ \\
\hline Tropical storm & 9634 & 1013 & $0.707 \pm 0.025$ & $10.3 \pm 1.1(8.5 \pm 1.5)$ \\
\hline Category $1-2$ hurricane & 4569 & 532 & $1.171 \pm 0.041$ & $11.1 \pm 1.2(8.6 \pm 1.2)$ \\
\hline Category $3-5$ hurricane & 2612 & 286 & $1.450 \pm 0.057$ & $12.2 \pm 1.3(9.5 \pm 1.7)$ \\
\hline Category $1-5$ hurricane & 7181 & 532 & $1.272 \pm 0.044$ & $11.5 \pm 1.2(9.0 \pm 1.4)$ \\
\hline All storms & 27735 & 1088 & $0.721 \pm 0.025$ & $10.7 \pm 0.9(8.8 \pm 1.2)$ \\
\hline
\end{tabular}

* The error bar of the maximum cooling is calculated by dividing its standard deviation by the square root of the number of storms (a lower bound for the number of independent observations).

** The figures outside the parentheses are obtained based on exponential fits of 30-day-long time series, while those inside are from fits of 14-day-long time series. The bounds reflect a $95 \%$ confidence level.

(Figs. 2, 3); this is more prominent for stronger TCs as the SSTA gradient in their induced normalized cold wake is larger in the cross-track direction (Figs. 3c,d). But both the quasi-linear relation for relatively weak winds and the level-off at high winds still exist, indicating these features are robust. The same behavior is observed separately for both the tropics and subtropics though a larger SST response can be found in the subtropics (Fig. 8b).

2) EXPLANATION OF THE QUASI-LINEAR RELATIONSHIP BETWEEN SSTA AND TC INTENSITY BASED ON A SIMPLE MIXED-LAYER MODEL

The observed quasi-linear relation between TC intensity and the maximum amplitude of its induced area-mean
SSTA is reproduced in a simple one-dimensional (vertical) model modified from Pollard et al. (1973), where mixed-layer depth and SST are obtained by imposing momentum and heat conservation when a wind stress is applied at the surface and vertical mixing is parameterized by converting shear kinetic energy into gravitational potential energy (see the appendix for details). The modeled maximum SSTA is

$$
\operatorname{SSTA}_{\max }=-\frac{1}{2 h_{\max }} \Gamma\left(h_{\max }-h_{\mathrm{cml}}\right)^{2} .
$$

Here $\Gamma$ is the prestorm vertical temperature gradient below the mixed layer, $h_{\mathrm{cml}}$ is the depth of the prestorm mixed layer, and $h_{\max }$ is the maximum depth of induced mixing:

\section{(a) SST response}

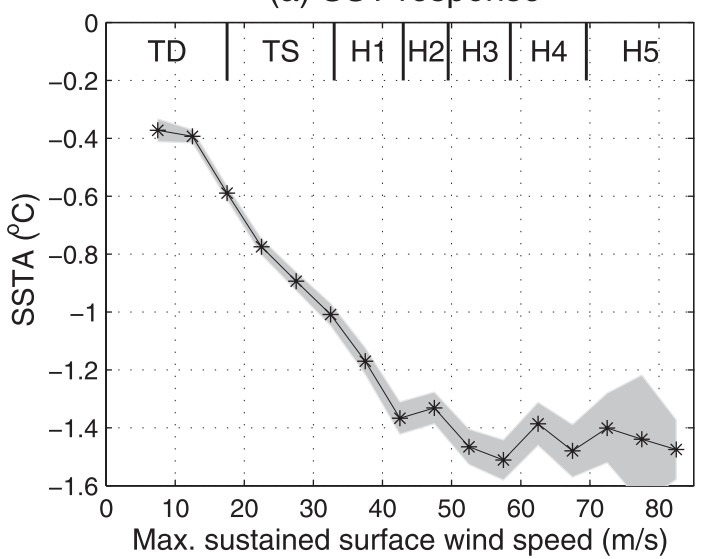

(b) Recovery e-folding time

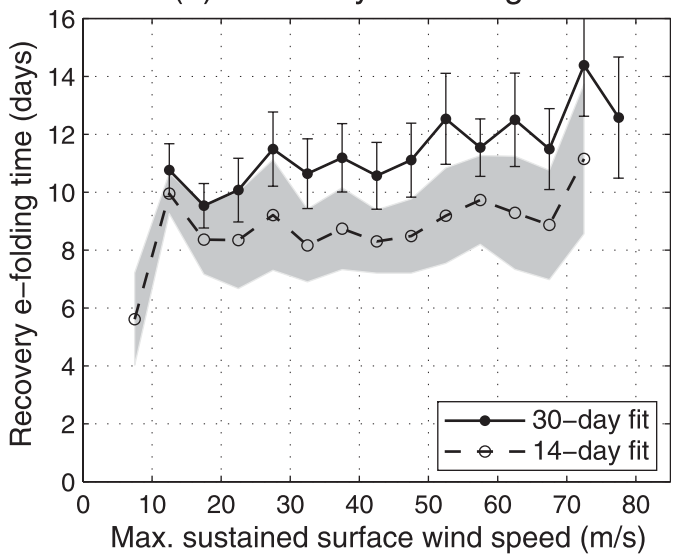

FIG. 7. (a) TC-induced maximum SSTA $\left({ }^{\circ} \mathrm{C}\right)$ averaged within a $5^{\circ} \times 5^{\circ}$ box as a function of the intensity of TC that is expressed as the maximum 1-min sustained surface wind speed $\left(\mathrm{m} \mathrm{s}^{-1}\right)$. Gray area shows the standard error of the composited maximum SSTAs, which is calculated by dividing their standard deviation by the square root of the number of storms (a lower bound for the number of independent observations). (b) As in (a), but for the recovery $e$-folding time scale of the SST obtained using a 2-week-long time series (dashed curve) and using a 1-month-long time series (solid curve). Shading and vertical bars show their respective error bars (with a $95 \%$ confidence level) for the fitted time scale. 
(a) Dependence on box size

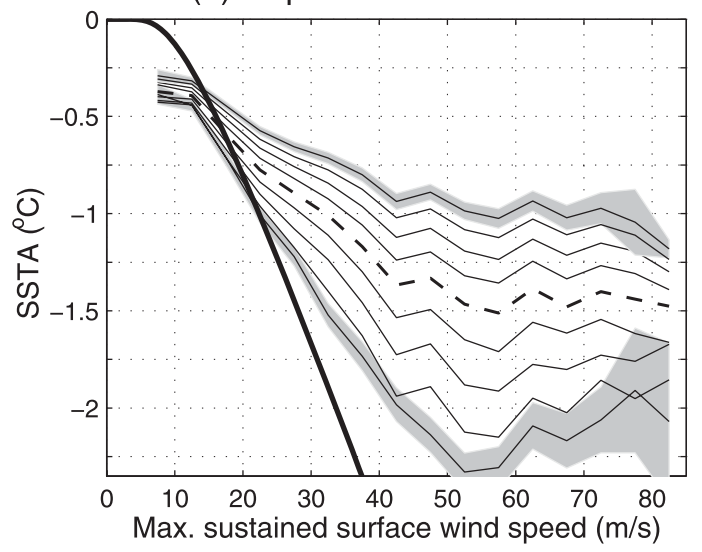

(b) Dependence on latitude

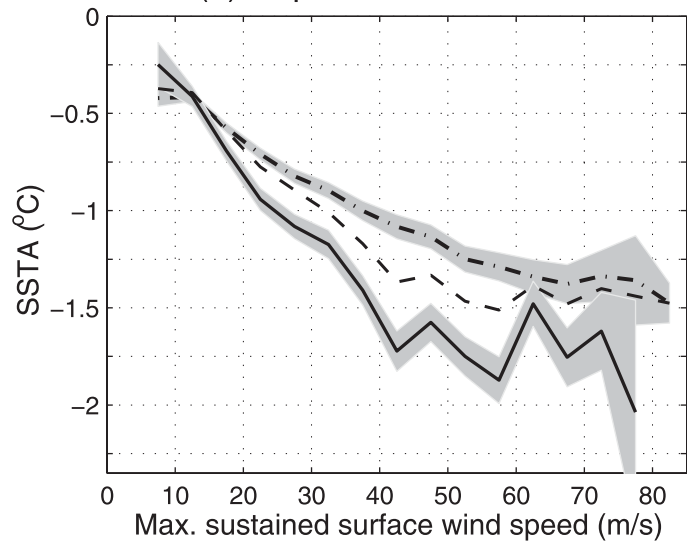

FIG. 8. (a) As in Fig. 7a, but for the maximum SSTA computed using boxes of different sizes. Thin solid curves from top to bottom are results from box with size of $9^{\circ} \times 9^{\circ}, \ldots, 6^{\circ} \times 6^{\circ}, 4^{\circ} \times 4^{\circ}, \ldots, 1^{\circ} \times 1^{\circ}$. Standard errors of the composite maximum SSTAs are shown for those calculated using $9^{\circ} \times 9^{\circ}$ and $1^{\circ} \times 1^{\circ}$ boxes as gray zones; the magnitude of standard errors for boxes of other sizes is generally in between. The thick solid curve is obtained from a simple mixed-layer model. (b) As in Fig. 7a, but for the maximum SSTA calculated for tropical area (dash-dotted curve) and subtropical area (solid curve).

$$
h_{\max }=\sqrt{\frac{h_{\mathrm{cml}}^{2}+\sqrt{h_{\mathrm{cml}}^{4}+\frac{32 \mathrm{Ri}\left(\rho_{a} C_{d} V_{s}^{2}\right)^{2}}{N^{2} f^{2} \rho_{o}^{2}}}}{2}},
$$

where Ri is the bulk Richardson number, $\rho_{a}$ is the air density, $C_{d}$ is the drag coefficient, $V_{s}$ is the surface wind speed, $N$ is the buoyancy frequency, $f$ is the Coriolis parameter, and $\rho_{o}$ is the seawater density.

The above two expressions connect the wind speed and the resultant SSTA. To graphically illustrate the results, we assign the involved variables with the following typical values: $h_{\mathrm{cml}}=25 \mathrm{~m}, \mathrm{Ri}=1, g=$ $9.8 \mathrm{~m} \mathrm{~s}^{-2}, \alpha=2 \times 10^{-4} \mathrm{~K}^{-1}, \Gamma=0.06 \mathrm{~K} \mathrm{~m}^{-1}, f=6 \times$ $10^{-5} \mathrm{~s}^{-1}, \rho_{a}=1.25 \mathrm{~kg} \mathrm{~m}^{-3}, \rho_{o}=1.025 \times 10^{3} \mathrm{~kg} \mathrm{~m}^{-3}$, and $C_{d}=2 \times 10^{-3}$. The obtained SSTA as a function of TC intensity is shown as a thick solid curve in Fig. 8a. It is clear that when the wind speed is greater than some threshold value so that efficient mixing is initiated, the model predicts a quasi-linear relation between the wind speed and the SSTA. Note that here we are not attempting to reproduce the exact details of the observed dependence of the SSTA on TC intensity; instead, we want to verify the proportionality between them with other factors being equal. The modeled quasi-linear relation is robust and holds when the details and the parameter values of the model are changed and/or a time-varying wind stress is used (see Figs. S1 and S2 in the supplemental material, where resonant behavior is also explored).

The simple model used here includes inertial oscillations and entrainment, but it misses many other processes, such as upwelling, air-sea heat fluxes, and changes in drag coefficient with surface wind speed, which might be important in setting the local oceanic response to intense winds (e.g., Price 1981; Ginis 2002; Walsh et al. 2010; Vincent et al. 2012). Here we provide a brief discussion on the potential influence of these factors. Exclusion of air-sea heat fluxes may significantly underestimate the SSTA generated by weak TCs such as tropical depressions, but its influence on stronger TCs is suggested to be minor (e.g., Price 1981; Vincent et al. 2012). Accordingly, we do not expect to see the nearly linear relationship predicted by the simple model to be significantly distorted when the air-sea heat fluxes are included, particularly for wind speed above hurricane intensity.

The dependence of the drag coefficient on wind speed is believed to be particularly important for strong winds like those associated with category 3-5 hurricanes, which are less efficient at transferring momentum into the ocean than weaker winds (e.g., Powell et al. 2003; Donelan et al. 2004; Jarosz et al. 2007). Here, to test the sensitivity of the simple model results to changes in drag coefficient, we use a modified Rankine vortex following Mueller et al. (2006) to mimic a TC and utilize a drag coefficient dependent on wind speed adapted from Walsh et al. (2010) (see the red curve in their Fig. 3). The SST response is then computed in uncoupled ocean columns at $1-\mathrm{km}$ resolution, each of them represented by the $1 \mathrm{D}$ model described above. While changes in the value of the drag coefficient are relatively important in determining the local SSTA (such as at the radius of maximum wind speed), their 
effects on the area-averaged SSTA are greatly reduced, and the quasi-linear relationship between SSTA and TC intensity is preserved (see Fig. S3 in the supplemental material).

Probably the biggest limitation of this simple model is its inability to represent upwelling processes. Indeed, recent work (Yablonsky and Ginis 2009; Halliwell et al. 2011; Chiang et al. 2011) suggests that 1D ocean models underestimate the TC-induced SST cooling as they exclude upwelling processes. This holds particularly true for slow-moving storms (e.g., Price 1981; Price et al. 1994) and/or shallow prestorm mixed layers (e.g., Halliwell et al. 2011), when the contribution of upwelling is comparable to that of entrainment (e.g., Yablonsky and Ginis 2009; Chiang et al. 2011). Chiang et al. (2011) attempted to separate out these two processes and found that the sum of the cooling caused by them can account for more than $90 \%$ of the total cooling, with the remainder attributed to their interaction and other processes. The amplitude of the SST cooling caused by upwelling may be assumed to be linearly proportional to the intensity of the TC that determines the strength of the upwelling (Price 1981), if other factors are fixed and the stratification below the prestorm mixed layer is constant; this, however, needs further confirmation from 3D sensitivity simulations.

The above discussion suggests that the surface cooling due to processes that are not represented in the simple model described above is either small or nearly linearly dependent on TC intensity. To first order, we thus expect a nearly linear relationship between the amplitude of the SST cooling and the TC intensity, as predicted by the simple model, when other factors, including the upper-ocean stratification and TC translation speed, are fixed. To confirm our expectation, we further performed numerical simulations using a 3D ocean model, the Regional Ocean Modeling System (ROMS), forced with a modified Rankine vortex model to mimic the wind field associated with a TC. The 3D model results (not shown) agree with the simple $1 \mathrm{D}$ model results in that the relationship between the TC intensity and the amplitude of the TC-induced area-averaged SST cooling is approximately linear. Such a relationship is indeed observed for relatively weak TCs (Fig. 7a). The interpretation of the observed level-off for the extremely high wind regime will be given after the exploration of the dependence of the SST response on the TC translation speed.

\section{b. Dependence on the translation speed of TCs}

Since the translation speed of a TC affects the local maximum amplitude of the TC-induced SSTA (section (a) Maximum SSTA

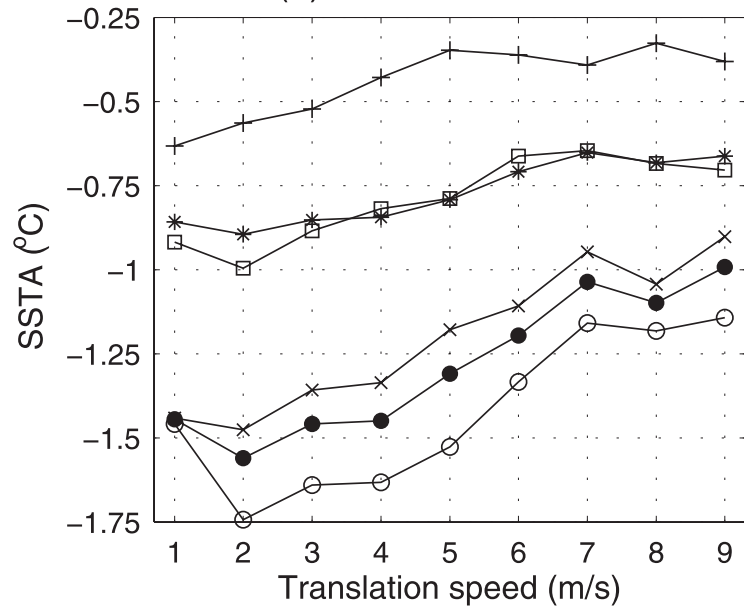

(b) Relative date of max. SSTA

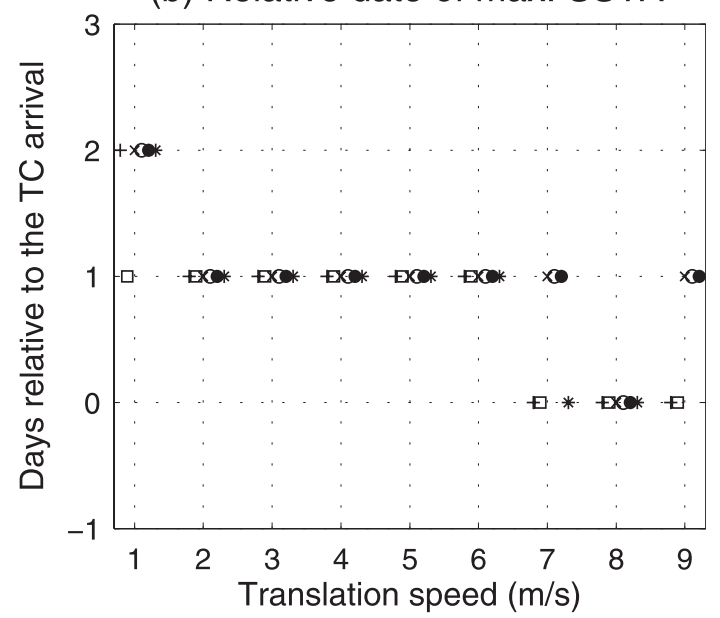

(c) Recovery e-folding time

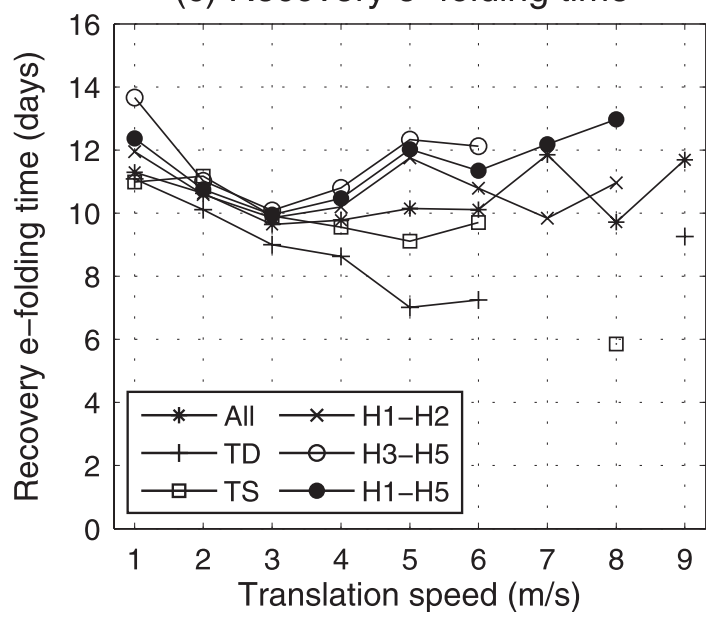

FIG. 9. (a) TC-induced maximum SSTA $\left({ }^{\circ} \mathrm{C}\right)$ averaged within a $5^{\circ} \times 5^{\circ}$ box as a function of the TC translation speed $\left(\mathrm{m} \mathrm{s}^{-1}\right)$ for TCs of different intensities. (b) As in (a), but for the date when the maximum SSTA appears relative to the arrival day of TCs. (c) As in (a), but for the recovery $e$-folding time scale calculated using 1-month-long SSTA time series. 
(a) Maximum SSTA

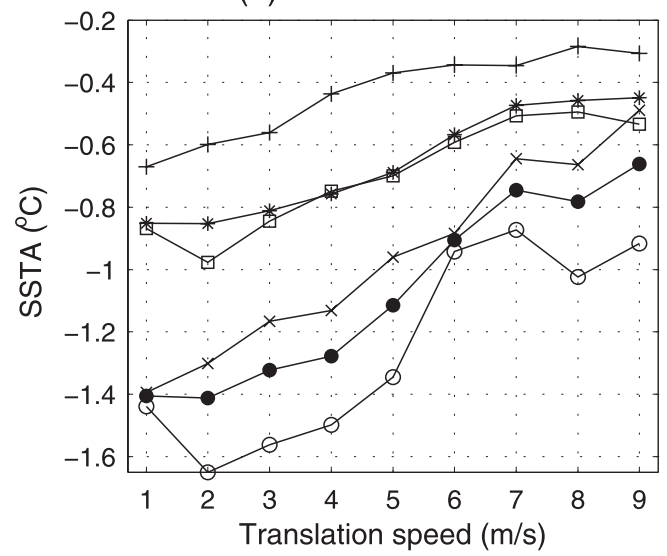

(c) Relative date of max. SSTA

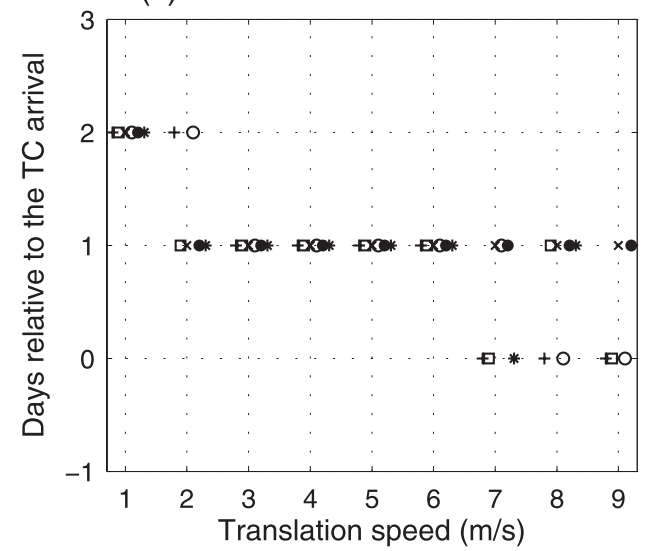

(b) Maximum SSTA

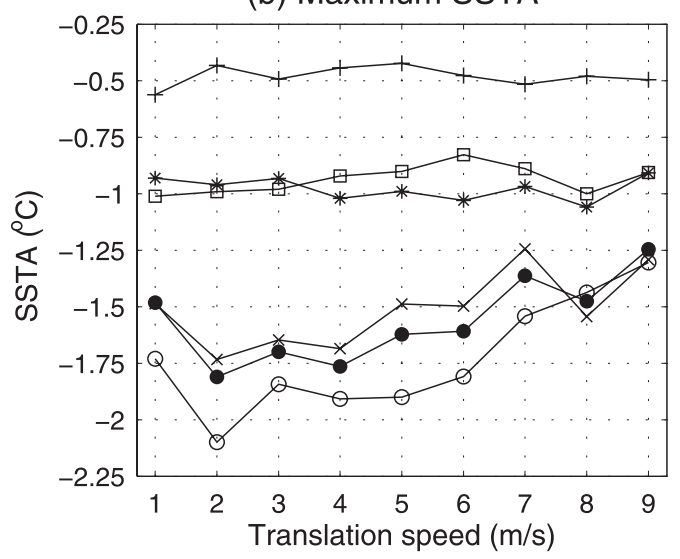

(d) Relative date of max. SSTA

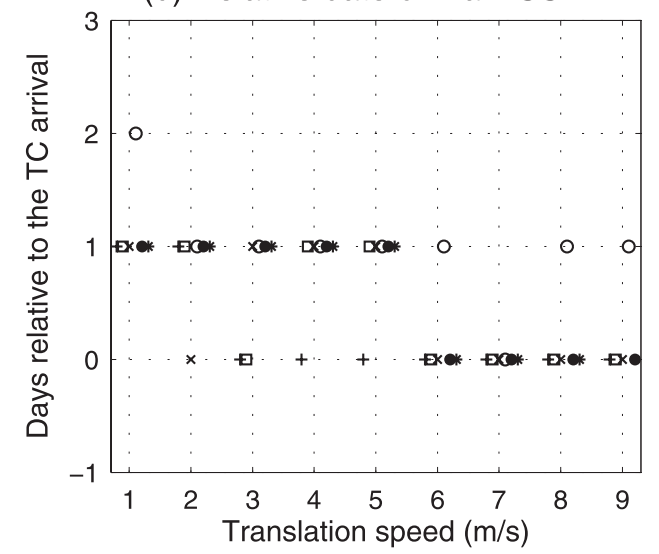

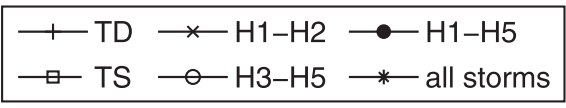

FIG. 10. (a),(b) As in Fig. 9a, but for (a) tropical region and (b) subtropical region. (c),(d) As in Fig. 9b, but for (c) tropical region and (d) subtropical region. Note the different scaling of the ordinates in (a) and (b).

3a), we expect it also affects the amplitude of the areamean SSTA. Figure 9a shows the maximum magnitude of area-mean SSTA as a function of translation speed for TCs of different intensities. As expected, for a given intensity, TCs moving slowly tend to induce larger SST response than those moving faster. For example, on average, a hurricane with a translation speed around $2 \mathrm{~m} \mathrm{~s}^{-1}$ produces an SSTA 1.6 times that generated by a TC of the same intensity but moving at a speed of $9 \mathrm{~m} \mathrm{~s}^{-1}\left(1.5^{\circ} \mathrm{C}\right.$ versus $\left.0.95^{\circ} \mathrm{C}\right)$.

The dependence of the amplitude of the SSTA on the TC translation speed can be explained as follows: slower-moving TCs have relatively longer residence time and result in larger vertical shear at the base of the mixed layer, and thus, they generate a deeper mixing and a stronger surface cooling (Zedler 2009). Also, slower-moving TCs extract heat from the ocean over a longer period of time and result in cooler surface water (Lin et al. 2009).

We further examine the dependence on translation speed separately for the tropical and subtropical regions. The dependence over the tropical area is more prominent than that considered over the total area. The maximum amplitude of the SSTA induced by a slowmoving hurricane can be as large as 2.2 times that generated by a fast-moving hurricane (solid curve with closed circles in Fig. 10a). Similar conclusions hold also for both tropical depressions and tropical storms.

In the subtropical area, the magnitude of the SST response (Fig. 10b) displays a much weaker dependence compared to its tropical counterpart. The maximum SSTA associated with the passage of a slow-moving hurricane is only about 1.4 times that induced by a fast-moving hurricane. What is more interesting is that there is 
almost no dependence on translation speed of the SST response for tropical depressions and tropical storms. To see at what latitude such transition from dependence to nondependence on translation speed occurs, we further repeat the calculations for each $5^{\circ}$-latitude band. The results show that equatorward of $17.5^{\circ}$, the dependence is present for storms of all categories. Between $17.5^{\circ}$ and $22.5^{\circ}$, the dependence is absent for tropical depressions, and poleward of $22.5^{\circ}$, we see no dependence for both tropical depressions and tropical storms.

We now give one plausible interpretation for the different dependence of SSTA on translation speed in the tropics and subtropics using the simple mixed-layer model discussed in the previous subsection and in the appendix. With persistent wind stress forcing, the modeled maximum SSTA occurs after a time interval $t_{m}=\pi / f$ from the time at which the wind starts blowing (here, $f=2 \Omega \sin \phi$ is the Coriolis parameter, with $\Omega$ the rotation rate of Earth and $\phi$ the latitude; see the appendix). Physically, $t_{m}$ is the time needed for inertial currents, which are responsible for the shear-induced vertical mixing, to fully develop. Up to that time, the wind-induced mixing depth increases and the SST correspondingly decreases; after $t_{m}$, even with sustained winds, the mixing depth and the SSTA do not change anymore. If the wind stress is applied for a time shorter than $t_{m}$, the mixing depth and the SSTA have not saturated yet and a shorter lasting wind stress results in a smaller cooling of the surface. At lower latitudes, $t_{m}$ is larger than at higher latitudes, and it can be longer than the residence time of a fast-moving hurricane, as the following calculation shows. Consider a TC with a typical length scale $L$ of $600 \mathrm{~km}$ (Fig. 6) (see also Dean et al. 2009; Park et al. 2011). Then, for a given translation speed $\left(U_{h}\right)$ at a given latitude $(\phi)$, we can calculate the TC residence time $\left(t_{r}=L / U_{h}\right)$, the time it takes for the maximum SSTA to be generated $\left[t_{m}=\pi /(2 \Omega \sin \phi)\right]$, and the ratio between them $\left(r=t_{r} / t_{m}\right)$. Figure 11 shows the ratio $r$ as a function of latitude and TC translation speed. It is clear that poleward of around $20^{\circ}$, even a TC with a translation speed of $10 \mathrm{~m} \mathrm{~s}^{-1}$ has a residence time longer than the time the maximum SSTA takes to develop, while in the tropics only slow-moving TCs have $r>1$. Regardless of its translation speed, every TC in the subtropical area resides at a given location for a time sufficient to generate the maximum possible SST response, while in the tropics fast-moving TCs are displaced from a location before their forcing has been long enough to saturate the SST response. This argument is further supported by the analysis of the appearing date of the maximum amplitude of the SSTA reported in section $5 b$.

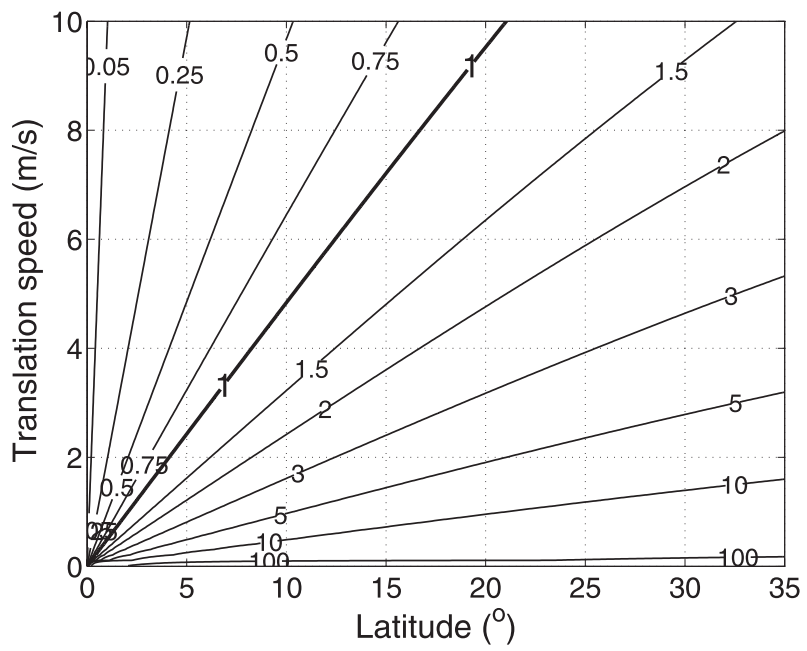

FIG. 11. Ratio between TC residence time and the time it takes the SSTA to reach its maximum as a function of latitude and TC translation speed (see the text for details).

\section{c. Discussion: Possible reasons for the observed level-off of SSTA in high-wind regime}

The results based on a simple model presented above suggest that the TC-generated SST reduction is almost linearly correlated with the TC wind speed when all other things are equal. Here we provide plausible interpretations on why, in the observations, the linear dependence does not hold for the extremely high wind regime.

\section{1) TROPICAL REGION}

As shown above, in the tropical region, the amplitude of the TC-induced SSTA strongly depends on TC translation speed: a faster-moving storm generates a much weaker SST cooling than a slower one of the same intensity (Fig. 10a). Moreover, we have shown in Mei et al. (2012) that in the tropics, a direct correspondence between TC intensity and translation speed exists, with stronger TCs moving faster than weaker ones. The reduction in SST cooling due to an increased translation speed for strong TCs effectively offsets the strengthened cooling due to intensified wind speed. As a result, the SST response does not increase as the TC wind speed increases. The details on this result are presented in Mei et al. (2012).

\section{2) SUBTROPICAL REGION}

In the subtropics, the magnitude of the SSTA weakly depends on TC translation speed (Fig. 10b). No good correspondence is found between TC intensity and its translation speed (not shown). Some other mechanism must be responsible for the level-off of the SSTA at high wind speeds. Given that in the subtropics the mixed 
(a)

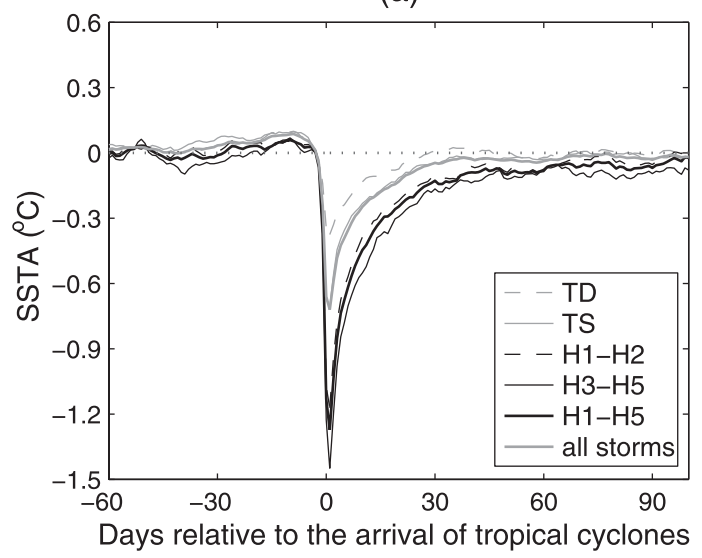

(b)

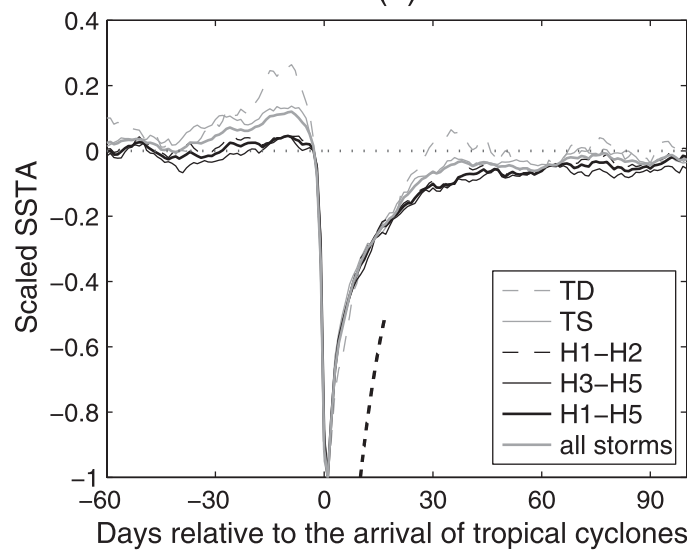

FIG. 12. (a) Evolutions of area-mean composite SSTA based on the TMI observations. (b) As in (a), but for scaled SSTA. In (b), all the SSTAs are scaled by their respective maximum cooling (see Table 2 for details). Thick black dashed curve in (b) indicates an exponential function with an $e$-folding time of 10 days.

layer is typically shallower than in the tropics, the system will be more sensitive here to the presence of warm ocean eddies, whose net effect is to deepen the prestorm mixed layer. For TCs moving over warm eddies, the mixing-induced drop in SST will be smaller, as can be deduced from Eq. (1) when a larger $h_{\mathrm{cml}}$ is used. Indeed, Lin et al. (2008) show that in the subtropics, all the TCs reaching a category 5 intensity had warm eddies along their tracks. We thus think that the level-off of the SSTA at high wind speeds in the subtropics has a different origin than the one in the tropics, and we agree with Lloyd and Vecchi (2011) that the dominant factor for the plateau here is the preferential presence of warm eddies under the TCs that reach high intensities.

\section{Temporal structure of the SST response}

\section{a. Overview}

The thick gray solid curve in Fig. 12a shows the temporal evolution of the composite SSTA averaged over a $5^{\circ} \times 5^{\circ}$ box based on all storms available using TMI observations and the area-mean procedure described in section 2. The SST starts to decrease 1 or 2 days before the TC passage, probably owing to horizontal advection (e.g., Huang et al. 2009). Using a different SST dataset, DM11 also find a notable cooling during the day before the TC passage. When the TC arrives, the mechanical mixing and the evaporation generated by strong winds further cool the surface water. Concurrently, those strong winds drive intense inertial currents in the upper ocean. The surface cooling is strengthened when the vertical shear of the inertial currents at the base of the prestorm mixed layer pushes the Richardson number below a critical value resulting in intense entrainment mixing (e.g., Sanford et al. 2011). The composite SSTA peaks during the day following the TC passage, while most of the cooling occurs during the day of TC passage. Right after the SST reaches its minimum, it begins to recover (Fig. 12a). The composite curve shows a rapid exponential adjustment at the beginning, followed by a more or less linear evolution. The major part of the cold anomaly dissipates within two weeks, a behavior that is broadly consistent with the results reported in Hart et al. (2007), P08, and DM11.

Around the average temporal evolution of the SSTA there exists large variability. By performing conditional composites, we will explore the dependence of the SST recovery on TC intensity and translation speed in detail later.

\section{b. Timing of area-averaged maximum amplitude}

Analysis of the temporal evolution of SSTA composited according to the TC intensity suggests that the SST reaches its minimum during the day right after the storm passage, independent of the storm intensity. This is easier to observe in Fig. 12b, which shows the temporal evolution of the normalized SSTA. This timing is consistent with the results of DM11, who, by examining the cases taking place between 1981 and 2008, show that the local maximum cooling occurs most commonly 1 day after the TC passage.

The timing of the maximum amplitude, however, depends on the TC translation speed (Fig. 9b). For extremely slow moving TCs, the maximum SSTA is present 2 days after the TC passage, while the SSTA associated with a fast-moving TC peaks during the passage day. For TCs moving at a translation speed between 2 and $7 \mathrm{~m} \mathrm{~s}^{-1}$, the SST drops to its minimum during the day 
right after the TC passage. This sensitivity to translation speed is likely associated with the fact that fastermoving TCs have relatively shorter residence time and thus result in a quicker emergence of the maximum SSTA [which is weaker than the maximum possible SSTA for a given wind intensity and ocean stratification attainable for long forcing times; see Eqs. (1) and (2)]. Note, however, that we cannot rule out the possibility that the different timing in the appearance of the maximum anomaly is an artifact of the lack of data under heavy rain conditions, which would last longer for slower-moving TCs.

Analysis of the timing separately for tropical and subtropical regions reveals that in the subtropics the SST often drops to its minimum 1 day earlier than that in the tropics (Figs. 10c,d), consistent with the shorter saturation time of SSTA $t=\pi / f$ at higher latitudes predicted by the simple model and discussed in section $4 \mathrm{~b}$.

\section{c. Recovery time scale of the area-mean SST}

As shown in Fig. 12, the cold anomaly of SST dissipates quickly during the first two weeks after the TC passage. To measure the restoration time scale more accurately, the time evolution of the composite SSTA of the first 30 days after the TC passage was fitted using a nonlinear least squares fit to an exponential curve with the following form:

$$
\operatorname{SSTA}(t)=A \exp \left(-\frac{t}{\Gamma}\right)
$$

The obtained recovery time $\Gamma$ is approximately 11 days (Table 2).

What is striking in Fig. 12b is that the evolutions of the scaled SSTA during the first two weeks after the passage of TCs of different intensities nearly overlap with each other, indicating the decaying rate of the normalized anomaly is almost independent of the magnitude of the SSTA, at least during the first two weeks. Fitting based on longer time series shows it takes slightly longer for the SSTA left behind stronger TCs to disappear, but the difference is small (Fig. 7b). The dependence of the recovery time on translation speed is also weak (Fig. 9c).

Attempts were also made to apply the same fitting procedure to individual cases, but with a constant $B$ added to the rhs of Eq. (3). In most cases, however, the time series of the SSTA is noisy, probably because of the contamination of many processes, such as the strong variability of wind stress, and as a result, the fit to an exponential is poor. The obtained probability density function of the $e$-folding times of individual cases is severely biased toward short times since the cases requiring longer time to recover are more vulnerable to the contamination. Despite this, some cases exhibit good exponential decay of
SSTA. Figure 13 shows three examples. Their $e$-folding times are about 3, 6, and 12 days. This suggests the recovery time of the SST varies considerably from case to case, in accord with the claims of P08 and DM11. The reason for such a large variance of SST recovery time may include, among others, high variabilities of wind stress, insolation, and cloud cover. Those processes dominate the variability, while the maximum magnitude of the SSTA is almost irrelevant. The atmospheric conditions responsible for the differences in the recovery time scale of individual cases are largely random and their mean effect is independent of TC characteristics.

\section{d. Temporal evolution of the spatial structure}

Figure 14 displays the temporal evolution of the composite cold wake left behind hurricanes in the Northern Hemisphere; the cold wakes of TCs of other intensities and in the Southern Hemisphere exhibit similar evolutions. The cold wake decays rapidly during the first several days after the SSTA peaks, and then it slowly declines, consistent with the evolution of the area-mean SSTA discussed in section 5a.

\section{1) EVOLUTION OF AVERAGED WIDTH OF COLD ANOMALY}

The thin white solid curves in Fig. 14 indicate the width of the normalized cold wake, which is defined at any time as the distance between points on each side of the track at which the SSTA equals the maximum SSTA divided by $e$ (see section 3c). While the magnitude of the anomaly still grows, the shape of the cold wake rapidly narrows from the day before the TC passage to the day after. This is due to the fact that the cooling rate is greater near the track than in surrounding regions. During the period of SST recovery, the cold wake is gradually decreasing in size in terms of the magnitude of the SST cooling, but the shape is actually getting wider, consistent with the idea of a larger dissipation of the larger anomalies and the diffusion of the cold anomalies induced by mesoscale and submesoscale eddies (e.g., Mei and Pasquero 2012). In addition, it is interesting to note that the cold wake is initially very asymmetric with respect to the TC track, owing to the shift of the cooling, and gets more and more symmetric during the recovery.

\section{2) EVOLUTION OF LOCATION OF MAXIMUM ANOMALY}

Accompanied by the gradual disappearing of the asymmetry in the cold wake, the maximum anomaly moves toward TC track during the first two weeks (see the thick white solid curve in Fig. 14 for the Northern Hemisphere; in the Southern Hemisphere, a similar movement is observed and not shown here). It keeps 
(a)

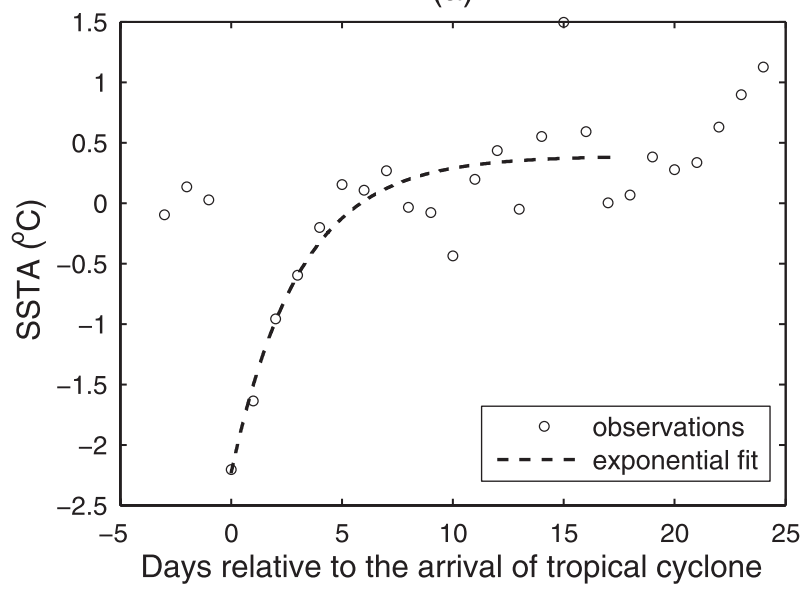

(b)

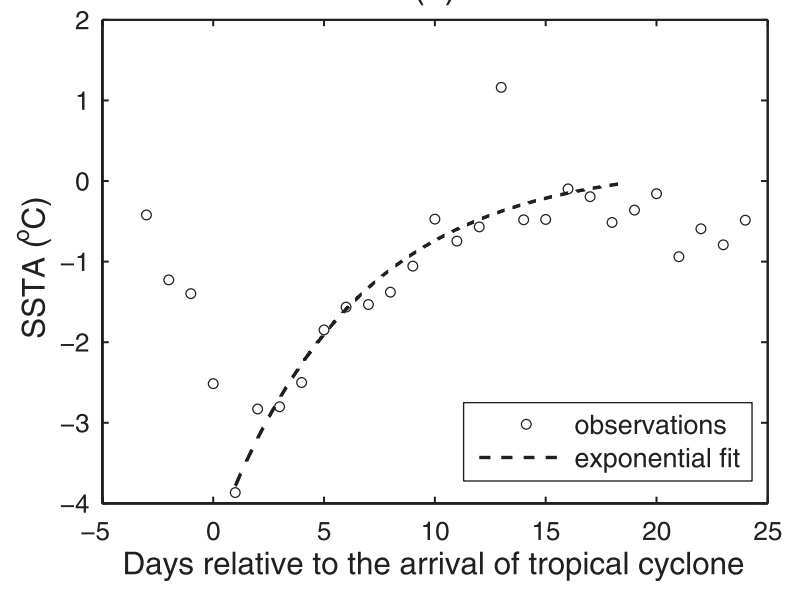

(c)

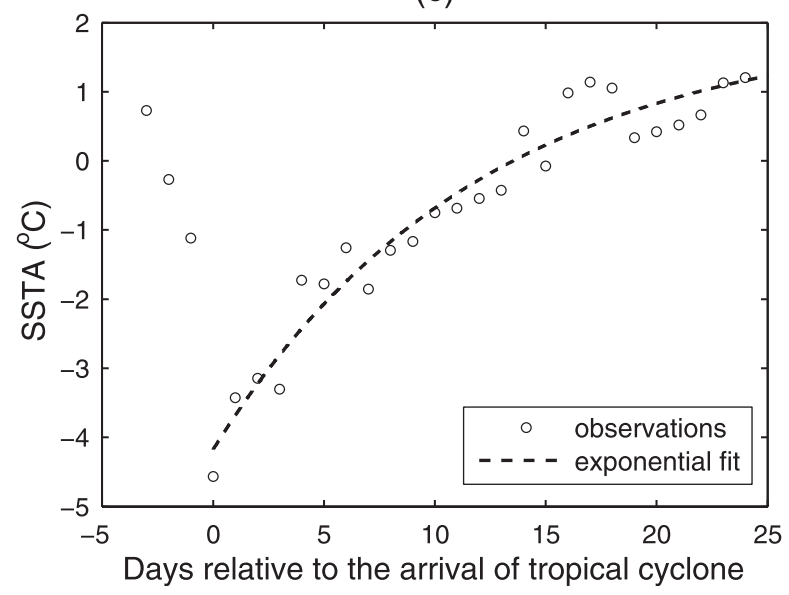

FIG. 13. Three cases with different recovery $e$-folding times. Circles are daily-mean TMI-observed SSTAs averaged over a $5^{\circ} \times 5^{\circ}$ box centered at (a) $21.5^{\circ} \mathrm{N}, 115.2^{\circ} \mathrm{E}$ after the passage of Typhoon Nuri on 22 Aug 2008; (b) $20.7^{\circ} \mathrm{N}, 122^{\circ} \mathrm{E}$ after the passage of Typhoon Mindulle on 30 Jun 2004; and (c) $23.8^{\circ} \mathrm{N}, 59.2^{\circ} \mathrm{E}$ after the passage of Cyclone Gonu on 16 Jun 2007. Dashed curves are the exponential fits with a form of $\operatorname{SSTA}(t)=A \exp (-t / \Gamma)+B$, where $A$ is $-2.62^{\circ},-4.01^{\circ}$, and $-6.17^{\circ} \mathrm{C}$ for (a), (b), and (c), respectively; $\Gamma$ is $3.07,6.30$, and 12.00 days, respectively; and $B$ is $0.39^{\circ}, 0.22^{\circ}$, and $1.99^{\circ} \mathrm{C}$, respectively.

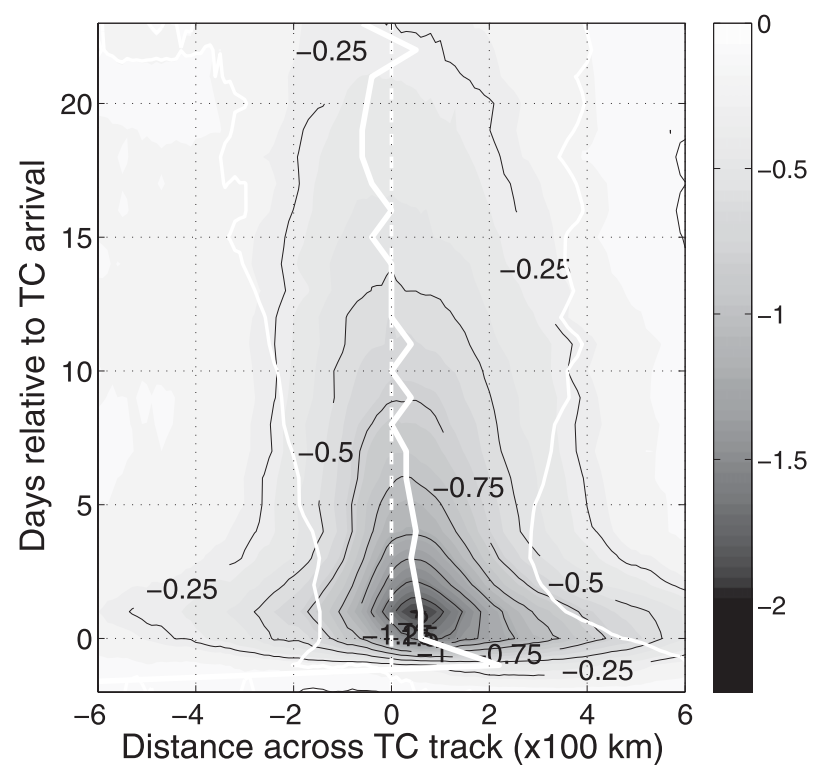

FIG. 14. Temporal evolution of the hurricane-induced cold wake in the Northern Hemisphere. Black contours show the SSTA $\left({ }^{\circ} \mathrm{C}\right)$. Thin white solid curves indicate the width of the normalized cold wake, which is defined at any time as the distance between points on each side of the track at which the SSTA equals the maximum SSTA divided by $e$ (see section 3c). Thick white solid curve shows the location of the maximum cold anomaly.

moving in the same direction after that. The rate of the movement is around $5.5 \mathrm{~km} \mathrm{day}^{-1}\left(\sim 0.05^{\circ} \mathrm{day}^{-1}\right)$. This is consistent with Jansen et al. (2010): using a composite based on a west-east section of SST, they find that the SSTA propagates westward at a rate of around $0.1^{\circ}$ day $^{-1}$, and they attribute the result to the propagation of a Rossby wave. The difference between the estimated rates is due to the fact that our estimate is relative to the TC track (in the Northern Hemisphere TCs typically move from south and/or east to north and/or west), while the estimate by Jansen et al. is along the east-west direction: the propagation rate that we find is a projection of the westward propagation rate onto the crosstrack direction.

\section{Summary and conclusions}

This study has examined the SST response to the passage of TCs by means of composite analysis using TMI SST data and the global TC best track dataset. By decomposing the response in an along-track and an across-track direction, we have been able for the first time to provide a complete characterization of the spatial structure of the TC-induced cold wake, including the maximum amplitude of the SSTA, its location, and the width of the wake. The area-mean maximum amplitude and the decay of the TCinduced SSTA have also been studied. The large dataset, 


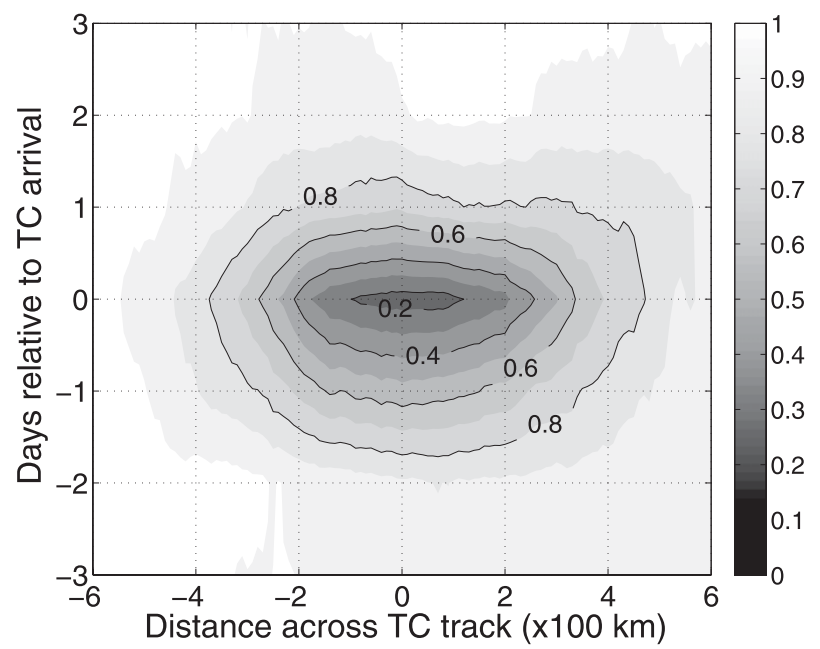

FIG. 15. The ratio of the number of available observations to the long-term mean number of observations as a function of cross-TCtrack distance and date relative to the TC passage for the situation of category 3-5 hurricanes in the Northern Hemisphere.

together with the composite technique, allows us to characterize not only the mean properties of the SST response, but also their dependence on TC intensity and translation speed, and on latitude as well. In some cases, our analysis confirms previous results from studies on a limited number of TCs, while in others, it provides new insights that were not known before.

It should be kept in mind that the maximum amplitude of the TC-induced SSTA may be underestimated in this study, though the SST data in use are more reliable than those used in many of the previous composite studies. As mentioned before, though the maximum amplitude emerges on the day after the TC passage, most of the cooling occurs during the day of the passage. However, we find that, in many cases, measurements near the TC track where maximum cooling is located are not available during the TC passage because of the adverse effect of heavy rains (see an example in Fig. 15 for the situation associated with category 3-5 hurricanes in the Northern Hemisphere). This may result in an underestimate of the amplitude of the cooling, as also indicated by a rough comparison between the observations (Figs. 10a,b) and results from Yablonsky and Ginis (2009) based on a 3D ocean model (see their Fig. 3). Correspondingly, the timing of the maximum amplitude of the SST cooling may be slightly delayed in our analysis. This, however, is hard to quantify owing also to the low temporal resolution of the TMI SST data. The estimate of the magnitude of these biases will require more complete observational datasets or specific modeling work.

With those cautions, we now summarize the main findings of this work. The composited spatial maps of
TC-induced SSTA show a prominent rightward (leftward) shifted cold wake with respect to the TC track in the Northern (Southern) Hemisphere, in accord with previous work. The local maximum cooling is located 50-60 km away from the TC track, almost independent of TC intensity and latitude. In contrast, its magnitude strongly depends on TC intensity and latitude: a category 3-5 hurricane typically produces a local cooling of $2.6^{\circ} \mathrm{C}$, while a tropical depression on average produces a cooling of a maximum of $0.5^{\circ} \mathrm{C}$ in the Northern Hemisphere; the local maximum amplitude of the cooling induced by TCs of the same intensity is larger at higher latitudes because of the shallower mixed layer. Both the location and amplitude of the local maximum cooling strongly depend on TC translation speed: a faster movement results in a stronger off-track shift but a weaker cooling. Analysis of the width of the cold wake suggests that stronger (or slower moving) TCs produce cold wakes of bigger size, but the shape of the wakes is very similar in all cases.

To better characterize the magnitude of the SST response to the TC passage, we calculated the maximum amplitude of the area-averaged SSTA, following the procedure described in Hart et al. (2007). The maximum amplitude of the areal mean SSTA nearly linearly correlates with the TC intensity for wind speed weaker than $50 \mathrm{~m} \mathrm{~s}^{-1}$. For the regime with higher wind speed, the TC-generated area-averaged maximum SSTA shows almost no changes as the wind speed increases. Both the linear relationship and the level-off are present in tropical (equatorward of $20^{\circ}$ latitude) and subtropical (between $20^{\circ}$ and $35^{\circ}$ latitude) subregions, but with a stronger SST response in the subtropical region that is due to the relatively shallower mixed layer in that region. A simple mixed-layer model modified from Pollard et al. (1973) can well explain the observed quasi-linear relationship in the relatively low wind regime and the latitudinal differences in the magnitude of the SSTA in response to TCs of same intensity.

Detailed examination of the dependence of the maximum amplitude of the TC-induced area-mean SSTA on the TC translation speed reveals that a strong dependence exists in the tropics with a slow-moving TC generating an SSTA more than 2 times that induced by a fast-moving one of same intensity. Such a strong dependence provides a basis for the interpretation of the level-off of the SSTA versus TC intensity observed in high-wind regime in this region, as stronger storms move faster, on average. In contrast, in the subtropics we see a rather week dependence of TC-induced SSTA on TC translation speed for hurricanes and no dependence for weaker TCs. In this area, the preferential presence of warm eddies under most intense storms, which increases 
the temperature of the water brought up to the surface by vertical mixing, appears to be the dominant contributor to the level-off in the maximum amplitude of the SSTA as a function of TC intensity, as suggested by Lloyd and Vecchi (2011). In other words, TCs that reach high intensities typically are those that move over warm eddies in the subtropics and are those that move fast in the tropics. Both mechanisms allow for generation of a relatively weak SSTA below the eye of the TC, which reduces the limiting effect of the interaction with the ocean on the intensification of the TC.

Exploration of the timing shows that, generally, the maximum amplitude of the TC-induced SSTA emerges on the day after the TC passage, independent of the TC intensity. However, this timing depends on the TC translation speed and latitude: the SSTA peaks earlier for faster-moving TCs (as the wind forcing does not last long enough for the maximum possible anomaly to be generated) and in the subtropics (as the inertial currents are faster generated at higher latitude, and they rapidly induce the shear-driven vertical mixing).

The area-averaged TC-induced SSTA largely decays within 1-2 weeks, with almost no dependence on the intensity of TCs and the magnitude of the anomaly. But, the recovery time of the SST has considerable case-tocase variability and is usually subject to environmental contaminations, including strong variations in wind strength and cloud cover.

Analysis of the temporal evolution of the composite cold wake reveals that the cold wake gets symmetric with respect to the TC track during the recovery period. It also shows that the location of the maximum cold anomaly with respect to the cyclone track moves toward the opposite direction of the initial shift at a rate of approximately $5.5 \mathrm{~km}$ day $^{-1}$.

This work provides new information on the important factors that shape the SST response to the TC passage, which has important impacts on both weather and climate. Hopefully, the characterization of the SST response to TCs given in this work will also promote a better understanding of the relative contribution to the recovery of the upper-ocean stratification of different processes, such as anomalous air-sea heat fluxes and adiabatic heat fluxes associated with baroclinic instability. Those processes have different impacts on the upper-ocean heat content and thus lead to potentially different indirect effects of TCs on climate.

Acknowledgments. This work was supported by NASA Headquarters under the NASA Earth and Space Science Fellowship Program (Grant NNX10AP30H). C.P. received partial funding from the Italian Ministry of Education, University, and Research as part of the
RITMARE project. We thank Prof. Francois Primeau for helpful discussions, and we thank the editor and the anonymous reviewers for their comments that greatly helped us improve the manuscript. We also thank Prof. Kerry Emanuel for sharing the compiled tropical cyclone best track data with modified wind speeds. TMI data are produced by Remote Sensing Systems and sponsored by the NASA Earth Science MEaSUREs DISCOVER Project. Data are available at www.remss.com.

\section{APPENDIX}

\section{Details of the Simple Mixed-Layer Model}

We consider a simple one-dimensional mixed-layer model modified from Pollard et al. (1973). The governing equations representing conservation of momentum and heat are

$$
\begin{gathered}
\frac{\partial(h u)}{\partial t}-f(h v)=\frac{\tau_{x}}{\rho}, \\
\frac{\partial(h v)}{\partial t}+f(h u)=\frac{\tau_{y}}{\rho}, \\
\frac{\partial(h T)}{\partial t}+\frac{\partial}{\partial t}\left[\frac{1}{2} \Gamma\left(h-h_{\mathrm{cml}}\right)^{2}\right]=\frac{Q}{c_{p} \rho}, \\
\operatorname{Ri}=\frac{g h \Delta \rho / \rho}{(\Delta u)^{2}}=\frac{g \alpha h\left[T+\Gamma\left(h-h_{\mathrm{cml}}\right)\right]}{u^{2}+v^{2}} .
\end{gathered}
$$

In the above equations, $T$ is the deviation of the mixedlayer temperature from its steady-state value, $h$ is the mixed-layer depth, $h_{\mathrm{cml}}$ is its steady-state value (i.e., the value before the TC passage), $\Gamma$ is the rate of temperature change in the vertical below the steady-state mixed layer, $Q$ is the anomalous net air-sea heat flux, and $\mathrm{Ri}$ is the bulk Richardson number; all other variables are defined conventionally.

To represent the effect of turbulent mixing, the bulk Richardson number is not allowed to become smaller than 1 , indicating that when the shear kinetic energy is large compared to the gravitational potential energy barrier at the base of the mixed layer, entrainment and mixing deepen the mixed layer.

The model is then run with a forcing that represents the effects of the passage of a TC. Since the contribution of net air-sea heat fluxes to the SST cooling is small compared to the contribution of the vertical mixing and entrainment within the upper ocean owing to the wind- and wave-generated and shear-induced turbulence (e.g., Price 1981), to the first order we assume $Q=0$ in Eq. (A2). Then we have 


$$
T=-\frac{1}{2 h} \Gamma\left(h-h_{\mathrm{cml}}\right)^{2}
$$

Physically, $Q=0$ implies heat conservation in the vertical column as the mixing depth increases [from which Eq. (A4) can be obtained] and no changes in $T$ when the mixing depth decreases. For this reason, the validity of this simple model is limited to the period of time of increasing $h$. When mixing depth decreases, the homogeneous surface layer does not change its temperature or its depth.

Assuming $\tau=\left(\tau_{x}, \tau_{y}\right)=\left(\tau_{0}, 0\right)$, the solutions to Eq. (A1) from Pollard et al. (1973) are

$$
\begin{aligned}
& h u=\frac{\tau_{0}}{f \rho} \sin (f t), \\
& h v=\frac{\tau_{0}}{f \rho}[\cos (f t)-1] .
\end{aligned}
$$

Substituting Eqs. (A4) and (A5) into Eq. (A3) and using $N^{2}=g \alpha \Gamma$, we obtain

$h=\sqrt{\frac{h_{\mathrm{cml}}^{2}+\sqrt{h_{\mathrm{cml}}^{4}+\frac{16 \mathrm{Ri} \tau_{0}^{2}}{N^{2} f^{2} \rho^{2}}[1-\cos (f t)]}}{2}}$.

If the forcing lasts for a time $t \geq \pi / f$, then the maximum possible mixing depth is attained:

$$
h_{\max }=\sqrt{\frac{h_{\mathrm{cml}}^{2}+\sqrt{h_{\mathrm{cml}}^{4}+\frac{32 \mathrm{Ri} \tau_{0}^{2}}{N^{2} f^{2} \rho^{2}}}}{2}} .
$$

Then, using the obtained $h_{\max }$ and Eq. (A4), we can get the maximum SST change that is reached at $t=\pi / f$, provided the forcing lasts for this time:

$$
T_{\max }=-\frac{1}{2 h_{\max }} \Gamma\left(h_{\max }-h_{\mathrm{cml}}\right)^{2} .
$$

\section{REFERENCES}

Bender, M. A., and I. Ginis, 2000: Real-case simulations of hurricaneocean interaction using a high-resolution coupled model: Effects on hurricane intensity. Mon. Wea. Rev., 128, 917-946.

_, _ and Y. Kurihara, 1993: Numerical simulations of tropical cyclone-ocean interaction with a high-resolution coupled model. J. Geophys. Res., 98, 23 245-23 263.

Black, P. G., and Coauthors, 2007: Air-sea exchange in hurricanes: Synthesis of observations from the coupled boundary layer air-sea transfer experiment. Bull. Amer. Meteor. Soc., 88, 357-374.
Black, W. J., and T. D. Dickey, 2008: Observations and analysis of upper ocean responses to tropical storms and hurricanes in the vicinity of Bermuda. J. Geophys. Res., 113, C08009, doi:10.1029/2007JC004358.

Brand, S., 1971: The effects on a tropical cyclone of cooler surface waters due to upwelling and mixing produced by a prior tropical cyclone. J. Appl. Meteor., 10, 865-874.

Brooks, D. A., 1983: The wake of Hurricane Allen in the western Gulf of Mexico. J. Phys. Oceanogr., 13, 117-129.

Carrigan, A. D., and M. L. Puotinen, 2011: Assessing the potential for tropical cyclone induced sea surface cooling to reduce thermal stress on the world's coral reefs. Geophys. Res. Lett., 38, L23604, doi:10.1029/2011GL049722.

Chiang, T.-L., C.-R. Wu, and L.-Y. Oey, 2011: Typhoon Kai-Tak: An ocean's perfect storm. J. Phys. Oceanogr., 41, 221-233.

Chu, J.-H., C. R. Sampson, A. S. Levine, and E. Fukada, 2002: The Joint Typhoon Warning Center tropical cyclone best-tracks, 1945-2000. NRL Reference Number NRL/MR/7540-02-16, 27 pp. [Available at http://www.usno.navy.mil/NOOC/nmfc-ph/RSS/ jtwc/best_tracks/TC_bt_report.html.]

Cione, J. J., and E. W. Uhlhorn, 2003: Sea surface temperature variability in hurricanes: Implications with respect to intensity change. Mon. Wea. Rev., 131, 1783-1796.

Dare, R. A., and J. L. McBride, 2011: Sea surface temperature response to tropical cyclones. Mon. Wea. Rev., 139, 3798-3808.

D'Asaro, E. A., 2003: The ocean boundary layer below Hurricane Dennis. J. Phys. Oceanogr., 33, 561-579.

— T. B. Sanford, P. P. Niiler, and E. J. Terrill, 2007: Cold wake of Hurricane Frances. Geophys. Res. Lett., 34, L15609, doi:10.1029/2007GL030160.

Dean, L., K. A. Emanuel, and D. R. Chavas, 2009: On the size distribution of Atlantic tropical cyclones. Geophys. Res. Lett., 36, L14803, doi:10.1029/2009GL039051.

de Boyer Montégut, C., G. Madec, A. S. Fischer, A. Lazar, and D. Iudicone, 2004: Mixed layer depth over the global ocean: An examination of profile data and a profile-based climatology. J. Geophys. Res., 109, C12003, doi:10.1029/2004JC002378.

Demuth, J., M. DeMaria, and J. A. Knaff, 2006: Improvement of advanced microwave sounder unit tropical cyclone intensity and size estimation algorithms. J. Appl. Meteor. Climatol., 45, 1573-1581.

Donelan, M. A., B. K. Haus, N. Reul, W. J. Plant, M. Stiassnie, H. C. Graber, O. B. Brown, and E. S. Saltzman, 2004: On the limiting aerodynamic roughness of the ocean in very strong winds. Geophys. Res. Lett., 31, L18306, doi:10.1029/2004GL019460.

Emanuel, K., 2001: Contribution of tropical cyclone to meridional heat transport by the oceans. J. Geophys. Res., 106,14 771-14 781.

Fedorov, A. V., C. M. Brierley, and K. Emanuel, 2010: Tropical cyclones and permanent El Niño in the early Pliocene epoch. Nature, 463, 1066-1070.

Ginis, I., 2002: Tropical cyclone-ocean interactions. AtmosphereOcean Interactions, W. Perrie, Ed., Advances in Fluid Mechanics Series, Vol. 33, WIT Press, 83-114.

Halliwell, G. R., Jr., L. K. Shay, and J. K. Brewster, 2011: Evaluation and sensitivity analysis of an ocean model response to Hurricane Ivan. Mon. Wea. Rev., 139, 921-945.

Hart, R. E., 2011: An inverse relationship between aggregate northern hemisphere tropical cyclone activity and subsequent winter climate. Geophys. Res. Lett., 38, L01705, doi:10.1029/ 2010GL045612.

, R. N. Maue, and M. C. Watson, 2007: Estimating local memory of tropical cyclones through MPI anomaly evolution. Mon. Wea. Rev., 135, 3990-4005. 
Hazelworth, J. B., 1968: Water temperature variations resulting from hurricanes. J. Geophys. Res., 73, 5105-5123.

Huang, P., T. B. Sanford, and J. Imberger, 2009: Heat and turbulent kinetic energy budgets for surface layer cooling induced by the passage of Hurricane Frances (2004). J. Geophys. Res., 114, C12023, doi:10.1029/2009JC005603.

Jacob, S. D., L. K. Shay, A. J. Mariano, and P. G. Black, 2000: The 3D oceanic mixed layer response to Hurricane Gilbert. J. Phys. Oceanogr., 30, 1407-1429.

Jansen, M., and R. Ferrari, 2009: Impact of the latitudinal distribution of tropical cyclones on ocean heat transport. Geophys. Res. Lett., 36, L06604, doi:10.1029/2008GL036796.

$\longrightarrow,-$, and T. A. Mooring, 2010: Seasonal versus permanent thermocline warming by tropical cyclones. Geophys. Res. Lett., 37, L03602, doi:10.1029/2009GL041808.

Jarosz, E., D. A. Mitchell, D. W. Wang, and W. J. Teague, 2007: Bottom-up determination of air-sea momentum exchange under a major tropical cyclone. Science, 315, 1707-1709.

Kimball, S. K., and M. S. Mulekar, 2004: A 15-year climatology of North Atlantic tropical cyclones. Part I: Size parameters. J. Climate, 17, 3555-3575.

Korty, R. L., K. A. Emanuel, and J. R. Scott, 2008: Tropical cycloneinduced upper-ocean mixing and climate: Application to equable climates. J. Climate, 21, 638-654.

Lachlan-Cope, T., and W. Connolley, 2006: Teleconnections between the tropical Pacific and the Amundsen-Bellinghausens Sea: Role of the El Niño/Southern Oscillation. J. Geophys. Res., 111, D23101, doi:10.1029/2005JD006386.

Leipper, D. F., 1967: Observed ocean conditions and Hurricane Hilda, 1964. J. Atmos. Sci., 24, 182-196.

Lin, I.-I., C.-C. Wu, I.-F. Pun, and D.-S. Ko, 2008: Upper-ocean thermal structure and the western North Pacific category 5 typhoons. Part I: Ocean features and the category 5 typhoons' intensification. Mon. Wea. Rev., 136, 3288-3306.

- I.-F. Pun, and C.-C. Wu, 2009: Upper-ocean thermal structure and the western North Pacific category 5 typhoons. Part II: Dependence on translation speed. Mon. Wea. Rev., 137, 37443757.

Lloyd, I. D., and G. A. Vecchi, 2011: Observational evidence for oceanic control on hurricane intensity. J. Climate, 24, 1138-1153.

Manzello, D. P., M. Brandt, T. B. Smith, D. Lirman, J. C. Hendee, and R. S. Nemeth, 2007: Hurricanes benefit bleached corals. Proc. Natl. Acad. Sci. USA, 104, 12 035-12 039.

Mao, Q., S. W. Chang, and R. L. Pfeffer, 2000: Influence of largescale initial oceanic mixed layer depth on tropical cyclones. Mon. Wea. Rev., 128, 4058-4070.

McAdie, C. J., C. W. Landsea, C. J. Neumann, J. E. David, E. Blake, and G. R. Hammer, 2009: Tropical Cyclones of the North Atlantic Ocean, 1851-2006. Historical Climatology Series, Vol. 6-2, NOAA, 238 pp.

Mei, W., and C. Pasquero, 2012: Restratification of the upper ocean after the passage of a tropical cyclone: A numerical study. J. Phys. Oceanogr., 42, 1377-1401.

,-- , and F. Primeau, 2012: The effect of translation speed upon the intensity of tropical cyclones over the tropical ocean. Geophys. Res. Lett., 39, L07801, doi:10.1029/2011GL050765.

Morey, S. L., M. A. Bourassa, D. S. Dukhovskoy, and J. J. O'Brien, 2006: Modeling studies of the upper ocean response to a tropical cyclone. Ocean Dyn., 56, 594-606.

Mueller, K. J., M. DeMaria, J. Knaff, J. P. Kossin, and T. H. V. Haar, 2006: Objective estimation of tropical cyclone wind structure from infrared satellite data. Wea. Forecasting, 21, 990-1005.
Nelson, N. B., 1996: The wake of Hurricane Felix. Int. J. Remote Sens., 17, 2893-2895.

Park, J. J., Y.-O. Kwon, and J. F. Price, 2011: Argo array observation of ocean heat content changes induced by tropical cyclones in the north Pacific. J. Geophys. Res., 116, C12025, doi:10.1029/2011JC007165.

Pasquero, C., and K. Emanuel, 2008: Tropical cyclones and transient upper-ocean warming. J. Climate, 21, 149-162.

Pollard, R. T., P. B. Rhines, and R. O. R. Y. Thompson, 1973: The deepening of the wind-mixed layer. Geophys. Fluid Dyn., 3, 381-404.

Powell, M. D., P. J. Vickery, and T. A. Reinhold, 2003: Reduced drag coefficient for high wind speeds in tropical cyclone. $\mathrm{Na}$ ture, 422, 279-283.

Price, J. F., 1981: Upper ocean response to a hurricane. J. Phys. Oceanogr., 11, 153-175.

— T. B. Sanford, and G. Z. Forristall, 1994: Forced stage response to a moving hurricane. J. Phys. Oceanogr., 24, 233-260.

— J. Jorzel, and P. P. Niiler, 2008: Warming of SST in the cool wake of a moving hurricane. J. Geophys. Res., 113, C07010, doi:10.1029/2007JC004393.

Pudov, V. D., 1993: The ocean response to the cyclones influence and its possible role in their track formation. Tropical Cyclone Disasters, J. Lighthill et al., Eds., Peking University, 367-376.

Sanford, T. B., J. F. Price, J. B. Girton, and D. C. Webb, 2007: Highly resolved observations and simulations of the ocean response to a hurricane. Geophys. Res. Lett., 34, L13604, doi:10.1029/2007GL029679.

$\ldots, \ldots$, and —_, 2011: Upper-ocean response to Hurricane Frances (2004) observed by profiling EM-APEX floats. J. Phys. Oceanogr., 41, 1041-1056.

Schade, L. R., 2000: Tropical cyclone intensity and sea surface temperature. J. Atmos. Sci., 57, 3122-3130.

_ , and K. A. Emanuel, 1999: The ocean's effect on the intensity of tropical cyclones: Results from a simple coupled atmosphereocean model. J. Atmos. Sci., 56, 642-651.

Schenkel, B., and R. Hart, 2010: An examination of the spatial and temporal extent of the climate memory of tropical cyclones. Preprints, 22nd Conf. on Climate Variability and Change, Atlanta, GA, Amer. Meteor. Soc., 112. [Available online at https://ams.confex.com/ams/pdfpapers/163674.pdf.]

— and - 2011: Potential precursors to and implications of tropical cyclone passage: A regional climate perspective. Preprints, 23rd Conf. on Climate Variability and Change, Seattle, WA, Amer. Meteor. Soc., 157. [Available online at https://ams.confex.com/ams/91Annual/webprogram/Handout/ Paper182841/seattle2011memory.pdf.]

Shay, L. K., P. G. Black, A. J. Mariano, J. D. Hawkins, and R. L. Elsberry, 1992: Upper ocean response to Hurricane Gilbert. J. Geophys. Res., 97, 20 227-20 248.

_, G. J. Goni, and P. G. Black, 2000: Effects of a warm oceanic feature on Hurricane Opal. Mon. Wea. Rev., 128, 1366-1383.

Sriver, R. L., and M. Huber, 2007: Observational evidence for an ocean heat pump induced by tropical cyclones. Nature, 447, $577-580$.

— , and —, 2010: Modeled sensitivity of upper thermocline properties to tropical cyclone winds and possible feedbacks on the Hadley circulation. Geophys. Res. Lett., 37, L08704, doi:10.1029/2010GL042836.

, - - and J. Nusbaumer, 2008: Investigating tropical cycloneclimate feedbacks using the TRMM Microwave Imager and the Quick Scatterometer. Geochem. Geophys. Geosyst., 9, Q09V11, doi:10.1029/2007GC001842. 
Stramma, L., P. Cornillon, and J. F. Price, 1986: Satellite observations of sea surface cooling by hurricanes. J. Geophys. Res., 91, 5031-5035.

Vincent, E. M., M. Lengaigne, G. Madec, J. Vialard, G. Samson, N. C. Jourdain, C. E. Menkes, and S. Jullien, 2012: Processes setting the characteristics of sea surface cooling induced by tropical cyclones. J. Geophys. Res., 117, C02020, doi:10.1029/ 2011JC007396.

Walsh, K. J. E., P. Sandery, G. B. Brassington, M. Entel, C. Siegenthaler-LeDrian, J. D. Kepert, and R. Darbyshire, 2010: Constraints on drag and exchange coefficients at extreme wind speeds. J. Geophys. Res., 115, C09007, doi:10.1029/ 2009JC005876.
Wentz, F. J., C. Gentemann, D. Smith, and D. Chelton, 2000: Satellite measurements of sea surface temperature through clouds. Science, 288, 847-850.

Yablonsky, R. M., and I. Ginis, 2009: Limitation of onedimensional ocean models for coupled hurricane-ocean model forecasts. Mon. Wea. Rev., 137, 4410-4419.

Zedler, S. E., 2009: Simulations of the ocean response to a hurricane: Nonlinear processes. J. Phys. Oceanogr., 39, 2618-2634. T. D. Dickey, S. C. Doney, J. F. Price, X. Yu, and G. L. Mellor, 2002: Analysis and simulations of the upper ocean's response to Hurricane Felix at the Bermuda Testbed Mooring site: 13-23 August 1995. J. Geophys. Res., 107, 3232, doi:10.1029/2001JC000969. 